\title{
Crisis por cooptación del cooperativismo agrario en Canarias: una interpretación desde la geografía agraria
}

\author{
Crisis due to co-optation of agricultural cooperativism \\ in the Canary Islands: an interpretation from agrarian geography
}

\author{
Víctor Onésimo Martín Martín ${ }^{1^{*}}$ (i) \\ Luis Manuel Jerez Darias² (10) \\ Luana Studer Villazán ${ }^{3}$ (D)
}

\section{Resumen}

Las crisis de las cooperativas agropecuarias canarias han sido cíclicas, coincidiendo con los períodos de recesión económica general, pero nunca habían alcanzado la magnitud de la de 2008. Por ello, y dada la efectiva importancia económica, social y territorial que este tipo de entidades tiene en el devenir del sector primario isleño, este artículo tiene como objetivo comprender cómo se ha llegado a la situación actual.

Las cooperativas, por formar parte de la economía social, son un instrumento que puede favorecer el desarrollo rural, y son en este sentido necesarias. La cuestión es quién dirige económica, social y políticamente las mismas. Se plantea que las cooperativas han terminado siendo cooptadas por la alianza entre los grandes propietarios rentistas y las grandes empresas comercializadoras de los productos de la agricultura de exportación y del mercado interior regional. En este proceso, dentro de las cooperativas canarias la pequeña agricultura familiar juega un papel subordinado, desnaturalizando los propios objetivos de este sistema asociativo. La consecuencia está siendo la disminución del tejido cooperativo por pérdida de socios o cierre de las cooperativas, a la vez que numerosas explotaciones familiares quiebran y desaparecen.

Palabras clave: cooperativismo; sistema agroalimentario; gran propiedad; comercio exterior; crisis económica; Canarias.

\footnotetext{
Abstract

The crises of the Canarian agricultural cooperatives have been cyclical, coinciding with periods of general economic recession, but they had never previously reached the magnitude of that of 2008. Given the effective economic, social, and territorial importance of this type of entity for the future of the local primary sector, this article aims to understand how the current situation has been reached.

Cooperatives, being part of the social economy, are an instrument that can promote rural development, and in this sense they are necessary. The question is who manages them economically, socially, and politically. We propose that the cooperatives have been co-opted by an alliance of large rentier owners

1 GISAS (Grupo de Investigación sobre el Subdesarrollo y el Atraso Social). Departamento de Geografía e Historia, Universidad de La Laguna (Tenerife, Islas Canarias, España). vbmartin@ull.edu.es. * Autor para correspondencia.

2 GISAS (Grupo de Investigación sobre el Subdesarrollo y el Atraso Social). Departamento de Geografía e Historia, Universidad de La Laguna (Tenerife, Islas Canarias, España). luisjerez@iriarteuniversidad.es

3 GISAS (Grupo de Investigación sobre el Subdesarrollo y el Atraso Social). Departamento de Geografía e Historia, Universidad de La Laguna (Tenerife, Islas Canarias, España). luanastuder@yahoo.es 
and large companies who market agricultural exports and sell to the regional internal market. In this process, small family farms play a subordinate role within Canarian cooperatives, and this distorts the very objectives of this associative system. The consequence is a reduction of the cooperative fabric due to a loss of members and the closure of the cooperatives, at the same time as numerous family farms go bankrupt and disappear.

Keywords: cooperativism, agri-food system, large property, foreign trade, economic crisis, Canary Islands.

\section{Introducción}

En el año 2007 se publicaba un libro que conmemoraba el sesenta aniversario de la creación de la entidad de economía social Sociedad Cooperativa Agrícola Cosecheros de Tejina, una de las cooperativas más representativas e importantes de la isla de Tenerife. Sólo seis años después la entidad entra en crisis y termina cerrando sus puertas. Junto a la anterior también van a quebrar la cooperativa Nuestra Señora de Abona (municipio de Arico), Cocarmen (Granadilla de Abona), la Quesería de Arico (Arico), y la Cooperativa de Benijos (La Orotava), que es "rescatada" por el Cabildo de Tenerife y "absorbida" por la Cooperativa Casmi de San Miguel. En total han cerrado cinco cooperativas agrarias en la isla de Tenerife entre 2009 y 2014.

La crisis económica mundial de 2008 trajo consigo la desaparición de numerosas cooperativas agrícolas de Canarias, en general, y de Tenerife, en particular. Mala gestión de sus directivas, excesivo endeudamiento, préstamos impagos, bajos precios de sus producciones agropecuarias fueron algunas de las causas esgrimidas para la crisis y cierre posterior de unas entidades de amplio arraigo en el campo de las Islas. Otras muchas, que se encuentran altamente endeudadas con las entidades financieras, han tenido que vender parte de su patrimonio, han perdido gran cantidad de socios por impagos a los mismos $y$, en consecuencia, ha descendido una parte importante de sus producciones agropecuarias, solicitando ayudas públicas para su supervivencia o llevando a cabo diversos expedientes de regulación de empleo.

Las crisis de las cooperativas agropecuarias canarias han sido cíclicas, coincidiendo con los períodos de recesión económica general, pero nunca habían alcanzado la magnitud actual. Por ello, y dado la efectiva importancia económica, social y territorial que este tipo de entidades tiene en el devenir del sector primario isleño ${ }^{4}$, merece la pena echar una mirada histórico-geográfica al cooperativismo con el objetivo de comprender mejor su situación actual.

\subsection{Estado de la investigación}

La mayor parte de las investigaciones sobre las cooperativas agrarias en España han sido elaboradas por economistas e historiadores de la economía, siendo la aportación de los geógrafos poco relevante.

En el caso español, y para no hacer excesivamente prolija las referencias, se remite a la principal revista española sobre Economía Social y Cooperativa (CIRIEC-España), en general, y a los trabajos de Garrido Herrero (2003) y Martínez Soto (2005) aparecidos en el número 44 de la misma.

En Canarias no existe un gran número de publicaciones científicas sobre el estudio de sus cooperativas. Dos de los principales investigadores de las mismas (Carnero Lorenzo y Nuez Yanes, 2015), señalan que el número ronda la quincena, siendo la mayoría de los trabajos de tipo económico sectorial o empresarial. Según dichos autores, la reducida nómina de cooperativas, comparada con la de otras regiones españolas, parece ser la causa de este tardío y escaso interés por el análisis de esta cuestión.

Las investigaciones hasta ahora realizadas tratan aspectos sectoriales o estudios de casos. Entre los primeros destacan los de la historia de las cajas rurales (Carnero Lorenzo y Nuez Yanes, 2002), y, en el segundo grupo, la obra que editó la Cooperativa Agrícola del Norte de Tenerife en 1964 con motivo de su cincuenta aniversario, el estudio de la cooperativa agrícola platanera Corporación de Agricultores (Román Cervantes y Bruno Pérez, 1999), el de la mayor cooperativa ganadera de Canarias, la Sociedad Cooperativa del Campo La Candelaria (Nuez Yanes y Carnero Lorenzo, 2004) y el de Sociedad Cooperativa

\footnotetext{
4 En el año 2013, la patronal de los agricultores y ganaderos canarios ASAGA/ASAJA señalaba como "el cooperativismo regional ha constituido, constituye y constituirá un pilar principal, aunque desaprovechado, del sector primario en las Islas" (Revista Campo Canario, 2013, 95, p. 3).
} 
Agrícola Cosecheros de Tejina (Nuez Yanes, 2007). Estos estudios no profundizan en la evolución del cooperativismo agropecuario regional.

En realidad, el primer texto sobre el cooperativismo en Canarias fue el de Delgado Aguilar (1991), aunque se trata de una colección de apuntes sobre la historia del cooperativismo en las Islas, partiendo en muchos casos de su experiencia personal. En el análisis económico y sociológico de las cooperativas canarias fue pionero el trabajo de Pérez Artiles (1991). Como señalan Carnero Lorenzo y Nuez Yanes (2005), se trata de un estudio pionero que, desgraciadamente, no ha recibido el reconocimiento científico y académico que merece, a pesar de que todos los estudiosos del tema hayan tomado buena nota de las aportaciones y conclusiones de dicho autor.

El artículo del historiador Suárez Bosa (1996) aborda el estudio de los sindicatos agrícolas en el primer tercio del siglo XX, utilizando exclusivamente documentación de los mismos. Los sindicatos agrícolas son también el objetivo de los trabajos de Román Cervantes (2001 y 2004). En el primero de los textos insiste en el reducido peso relativo de Canarias en el total nacional y en la debilidad del movimiento asociativo en el Archipiélago; luego, el autor analiza la evolución del asociacionismo agropecuario desde los años cuarenta en adelante. Destaca en su segundo trabajo el apartado dedicado a las sociedades agrarias de transformación (SAT) y concluye afirmando que el asociacionismo agropecuario en Canarias se ha consolidado, buscando maximizar el beneficio, reducir de los costes unitarios y tendiendo hacia la fusión en entidades de mayor tamaño. En un artículo posterior, Román Cervantes (2007) muestra como el perfil de las cooperativas canarias se caracteriza por su carácter exportador y de comercialización de sus productos agrarios. Más recientemente este director de la cátedra de Economía Social y Cooperativa de la Universidad de La Laguna ha publicado trabajos sobre el cooperativismo español (Román Cervantes, 2008 y 2014).

Otro grupo de investigaciones son las desarrolladas por F. Carnero Lorenzo y J. S. Nuez Yanes. Destacan sus trabajos sobre la historia económica del asociacionismo agrario en Canarias en los que se recogen aspectos teóricos e hipótesis sugerentes, así como una recopilación bibliográfica de lo publicado sobre el tema (Nuez Yanes y Carnero Lorenzo, 2005a; Nuez Yanes, Carnero Lorenzo y Barroso Ribal, 2005; Carnero Lorenzo y Nuez, 2015). Otras aportaciones enmarcan el desarrollo del cooperativismo de crédito agrícola (Carnero Lorenzo y Nuez Yanes, 2002) o economía social y empleo (Carnero Lorenzo, Barroso Ribal y Nuez Yanes, 2014). Por último, varias de sus publicaciones recogen aspectos del asociacionismo agrario en relación al cultivo del plátano (Nuez Yanes y Carnero Lorenzo, 2005b; Nuez Yanes, 2005).

La Geografía, sin embargo, se ha ocupado poco de los problemas de la Economía social, tanto en su vertiente clásica o convencional como en la alternativa. En América Latina existen algunos trabajos que tratan de evaluar la relación entre la Geografía y los procesos cooperativos alternativos al sistema capitalista globalizado. Uno de ellos (Jurado y Cardozo, 2016) aporta cuestiones teóricas de interés para esta disciplina. El geógrafo español R. Méndez presentó un trabajo pionero sobre las nuevas formas de Economía Social que se pueden denominar como Economía Social Solidaria (ESS) a raíz de la crisis mundial de 2008 y como resiliencia y/o alternativa a la expansión del neoliberalismo, aunque su estudio está más referido al ámbito urbano (Méndez, 2015).

Si los trabajos de los geógrafos sobre Economía Social, en general, son pocos, los que tratan sobre las cooperativas agrícolas en España son bastante escasos. Una de esas investigaciones de los geógrafos en el Estado es el trabajo pionero de A. Gil Olcina sobre el impacto de las cooperativas en la organización de las áreas rurales (Gil Olcina, 1989). Años después y dirigida por ese mismo profesor es la tesis doctoral de C. Basanta de la que se han publicado algunos artículos (Basanta Fernández, 2012). Pero es la obra del profesor alicantino J. A. Segrelles donde se puede encontrar el mayor número de trabajos de un geógrafo español sobre las cooperativas, fundamentalmente las ganaderas (Segrelles Serrano, 1992, 1994 y 1999; Segrelles Serrano y Maas, 1996). Más recientemente destacan los trabajos de J. D. Gómez que indaga sobre las cooperativas, valencianas principalmente, y las políticas agrarias comunitarias (Gómez López, 2004a y 2004b).

En Canarias, el trabajo de Geografía más representativo en este aspecto lo constituye la tesis doctoral de Wladimiro Rodríguez. Este geógrafo aporta una información interesante, aunque ya necesitada de actualización, de la importancia nada desdeñable de las cooperativas agrícolas en la agricultura de exportación de Canarias (Rodríguez Brito, 1986). 


\subsection{Propósito, objetivo e hipótesis}

Es evidente y reconocido que el sistema de cooperativas agrarias ha tenido y tiene una proyección socio-económica y territorial destacada, contribuyendo al mantenimiento de los modos de vida y cultura locales. Otro tema es hasta qué punto esa economía cooperativa ha sido beneficiosa o no y si ese modo de vida y cultura local que se ha mantenido y mantiene en las áreas rurales caminan en un sentido de progreso general de las comunidades o sólo beneficia a grupos determinados. Este artículo tiene como propósito contribuir a mensurar esta pregunta, mediante el estudio de lo acontecido en el Archipiélago Canario, en general, y en la isla de Tenerife, en particular. Su justificación viene dada además por el intento de contribuir a esclarecer las causas de la crisis sobrevenida en muchas cooperativas de las islas en los últimos años, coincidiendo con la crisis mundial de 2008, la consecuente remodelación del sistema cooperativo y su adaptación a las nuevas transformaciones del sistema agroalimentario en Canarias.

Este objetivo se llevará a cabo a través del prisma de la Geografía Agraria, pues la mayor parte de los trabajos realizados hasta el momento en Canarias han sido obra de economistas, historiadores de la economía e historiadores. Por tanto, la visión espacial (localización de las actividades agropecuarias y de las cooperativas) y escalar (escala local, insular, regional estatal, UE y mundial) permearán el trabajo para comprender un poco mejor, sin olvidar la dimensión histórica, las relaciones entre el territorio y el fenómeno cooperativo.

Históricamente, el sistema agroalimentario en Canarias ha beneficiado a los agentes comerciales locales y foráneos y al Estado, a cambio de compensar a los grandes agricultores, dueños de la tierra y el agua, dedicados a producir para exportar. Y como la economía canaria se ha basado desde siempre en su carácter exportador (caña de azúcar en el siglo XVI, vino en el XVII, cochinilla en el XIX, plátano, tomate y papas ${ }^{5}$ en el XX, turismo en el XXI), el control de su comercio exterior lo decide todo. El propio desarrollo normativo actual refrenda dicha afirmación (REF, POSEICAN y REA). Estos agentes comerciales (empresas importadoras, a las que se han unido las grandes cadenas de supermercados a partir de su llegada en los años noventa del pasado siglo) tienen una posición de fuerza nunca antes vista en el sistema agroalimentario canario.

Por tanto la hipótesis es que, en primer lugar, las cooperativas canarias han sido entidades controladas por los grandes propietarios locales, aliados éstos con las empresas comerciales importadoras y exportadoras (locales y foráneas) y del Estado (en su vertiente central y autonómica). En segundo lugar se intentará demostrar como las cooperativas fracasaron en las tres ocasiones históricas que intentaron alcanzar cierto dominio del mercado exterior canario (fracaso de la generación de una burguesía agraria), volviendo a depender con mayor profundización de las empresas comercializadoras foráneas. Las fases de crisis lo que han hecho es concentrar el poder de los medianos y grandes agricultores. El resultado ha sido la pérdida de su poder de decisión en las cooperativas, cuando no la pérdida de sus tierras o el abandono de sus explotaciones. Hay pues que entender el tejido cooperativo canario como un proceso, y, por tanto, no es cierto que las cooperativas representen hoy un elemento que haya permitido el crecimiento de la riqueza y la articulación de las áreas rurales.

Las cooperativas son un instrumento que puede favorecer el desarrollo rural, y son en este sentido necesarias. El problema es quién dirige económica, social y políticamente las mismas.

\section{Metodología}

Las cooperativas agrarias forman parte del entramado de la Economía Social, la cual puede definirse como el conjunto de actividades económicas y empresariales, que en el ámbito privado llevan a cabo aquellas entidades que persiguen bien el interés colectivo de sus integrantes, bien el interés general económico o social, o ambos.

El precedente jurídico más claro de los orígenes del cooperativismo español es la Ley de Sindicatos Agrícolas, promulgada el 28 de enero de 1906 y como señalaba en 2015 la entonces ministra de Agricultura:

Han pasado casi 110 años y es una realidad innegable que el espíritu asociativo haya calado en los productores agrícolas. Actualmente son 3.838 las cooperativas existentes en España, que agrupan a 1.175.000 socios agricultores, y dan empleo directo a cerca de 100.000 personas, facturando

5 Papas es el término común empleado en Canarias para referirse a las patatas. 
26.183 millones de euros al año. Cifras muy significativas, que indican la gran participación del sector cooperativo en la producción final agraria y en las ventas de la industria agroalimentaria (Gómez, 2015, p. 19).

Entre los objetivos de las cooperativas agrícolas, se destacan aquellos que mejor definen su actividad: el empaquetado, transporte, exportación y venta a cargo de los asociados de los productos obtenidos en sus cosechas; la compra y abastecimiento para la cooperativa o para los socios, de abonos, semillas, plantas, animales, maquinaria, aperos, insecticidas, y demás inputs de producción; y, por último, colaborar con las distintas cooperativas con el objetivo de reducir los costes de producción, venta y exportación, con la posibilidad de formar parte de entidades de mayor tamaño (Román Cervantes, 2007).

Para responder a las cuestiones planteadas en la hipótesis se han utilizado una serie de fuentes que se pasan a pormenorizar. Las fuentes bibliográficas, aunque todavía poco numerosas como se advirtió más arriba, han servido para comprender la evolución y estado actual de las cooperativas tanto en sus aspectos cuantitativos como cualitativos. Y aunque los investigadores de las cooperativas canarias coinciden en señalar la complejidad para la obtención de fuentes cuantitativas en cuanto a las principales magnitudes socioeconómicas (Carnero Lorenzo, Barroso Ribal y Nuez Yanes, 2014), se cuenta con una información suficiente en los trabajos publicados.

La principal fuente de información utilizada ha sido la prensa periódica regional. En ella se encuentra cuantiosa información a lo largo del tiempo relacionada con las cooperativas. Incluso en las últimas décadas cuando ya la agricultura en Canarias aporta poco valor al P.I.B. regional, las noticias sobre cooperativas agrícolas son numerosas. El tipo de información que se localiza en las fuentes periodísticas va desde datos sobre estas entidades (número de asociados, producción, facturación, exportación, etc.) hasta descripciones de su historia (fecha de creación, evolución temporal, juntas directivas, etapas críticas y de bonanza), pasando por informaciones coyunturales muy importantes sobre todo en las etapas de crisis (causas de la crisis, pérdidas, regulaciones de empleo, abandono de socios), entrevistas a presidentes, gerentes, directivos y socios, y artículos de opinión de expertos en cooperativas o de personas vinculadas a las políticas agrarias.

Otra importante fuente de información utilizada ha sido las publicaciones en papel y digitales de revistas agrícolas y periódicos digitales de Canarias sobre temas agrarios (ver en apartado final de referencias bibliográficas). Aunque no todas las tienen, útiles han sido también las webs de las cooperativas agrarias, pero no todas ellas están actualizadas o contienen amplia información. En estas fuentes se aportan encontrado datos cuantitativos y cualitativos similares a los de la prensa periódica, aunque en las revistas y webs se nota más claramente la línea editorial de defensa a ultranza de las cooperativas y aparecen menos las polémicas de las cooperativas, sobre todo en épocas de crisis.

Por último, además de la propia experiencia de uno de los autores de este artículo de haber sido parte de una familia de cooperativista, se ha consultado diversa documentación estadística (Instituto de Estadística de Canarias ISTAC: http://www.gobiernodecanarias.org/istac/estadisticas/sectorprimario/agricultura/ agricultura/E30042A.html; Información del Mundo Rural de Tenerife: http://www.agrocabildo.org/; Mapa de Cultivos de Canarias de la Consejería de Agricultura, Ganadería y pesca del Gobierno de Canarias: https://www.gobiernodecanarias.org/agricultura/temas/mapa_cultivos/) y normativa sobre cooperativas (documentos de las leyes de cooperativas estatales publicadas en el BOE y autonómicas publicadas en el BOC) y también se ha llevado a cabo diversas entrevistas a expertos en este campo (entrevistas abiertas semiestructuradas: Ángela Delgado, presidenta de la Cooperativa LACASMI del municipio tinerfeño de San Miguel de Abona y presidenta de Asaga-Canarias; entrevistas a cooperativistas; entrevista al agricultor, cooperativista y geógrafo W. Rodríguez Brito).

El objetivo principal de la consulta de todas estas fuentes ha sido siempre comprender el proceso evolutivo y las causas del estado actual del entramado cooperativo agrícola en Canarias, por lo que, siendo importante lo cuantitativo, lo ha sido más lo cualitativo. Y todo ello para abrir nuevas puertas a la investigación sobre la agricultura canaria y el papel del cooperativismo en ella.

\section{Resultados: caracterización de la agricultura y del cooperativismo en Canarias}

Han existido tres subsectores de la economía agraria donde las cooperativas han jugado un papel nada desdeñable: la producción y exportación de plátanos, tomates y papas, aunque este último cultivo ha derivado cada vez más hacia el mercado isleño. La histórica extroversión de la economía del archipiélago ha 
sido la llama donde ha prendido el sistema cooperativo, mientras que la producción para el mercado interior ha quedado descuidada hasta tiempos recientes en que se ha intentado vehicular a través del sistema cooperativo cierta producción hacia lo que hoy se llamaría soberanía alimentaria. Este reciente cambio de rumbo del sistema cooperativo se ha dado en las antiguas cooperativas dedicadas a la exportación de papas y de tomates, ante la pérdida de los mercados exteriores y el descenso de sus producciones.

\subsection{Para entender el cooperativismo canario: Historia económica de la agricultura canaria contemporánea}

En este período de poco más de un siglo, la historia económica de Canarias puede dividirse en tres etapas claramente relacionadas con su comercio exterior: 1900-1945, 1945-1986 y 1986 en adelante. Cada una de las etapas presenta un inicio, un desarrollo y termina en crisis.

\subsubsection{Primera etapa (1900-1945). El dominio del imperialismo británico en la economía canaria}

Históricamente, el sector agrario canario había estado estructurado en dos renglones productivos: la agricultura de exportación y la agricultura de subsistencia-mercado interior. Así, mientras una parte de la producción se había orientado a la obtención de artículos con un alto valor de cambio en los mercados exteriores (agricultura de exportación: caña de azúcar en el siglo XVI, vino en el XVII, grana o cochinilla en el XIX, plátanos, tomates y papas en el XX), para poder adquirir aquellos bienes que no pudieran lograrse en el interior (manufacturas), la otra se había dedicado a la producción para el mercado interno y a garantizar el abastecimiento de productos primarios a la población (cereales, papas, ganadería-pesca y frutas-hortalizas). Con el comienzo de la fase imperialista del capitalismo, este modelo comenzó a descomponerse a lo largo de la segunda mitad del XIX y que aceleró su proceso de ruptura a partir de 1900. Siguiendo a Carnero Lorenzo y Nuez Yanes (2015) la burguesía agrocomercial canaria encontró en las importaciones de ultramar la posibilidad de reducir sus costes salariales, aprovechando los menores precios de las manufacturas y de los alimentos de la desarrollada industria y agricultura europea, a la par que incrementar sus ingresos con la distribución en el mercado interinsular de las subsistencias foráneas, por lo que consiguieron la eliminación de los aranceles que aún existían sobre los cereales en el régimen puertofranquista isleño. Éste fue el punto de partida de un proceso de paulatina decadencia y pérdida de peso en el esquema económico canario de la agricultura para el mercado interno, aunque no desapareció la agricultura de autosubsistencia, ya que también servía para reducir los costes salariales del incipiente capitalismo canario.

A la par que la decadencia de esos artículos, se produjo la expansión de la producción hortofrutícola para la exportación. Una expansión promovida y financiada en buena parte por las navieras europeas, principalmente británicas, que habían hecho de la infraestructura portuaria del Archipiélago base de aguada y carboneo en sus periplos transatlánticos (Suárez Bosa, Martínez Milán, Luxán Meléndez y Solbes Ferri, 1995). Para llenar los huecos vacíos en los viajes de retorno de las colonias a las metrópolis, ofrecieron a la terratenencia isleña el crédito necesario para la puesta en marcha de las explotaciones de tomates y plátanos, y la garantía de compra de toda la cosecha. Si así se iniciaba el cultivo de estos artículos, poco a poco se fueron sumando empresas locales a las labores de intermediación, y el tejido bancario autóctono se vinculó a ese sector exportador. Así pues, no había problemas de financiación ni de comercialización, y en cuanto al suministro de inputs, las empresas de servicios cubrían la demanda a precios suficientemente interesantes (Carnero y Nuez, 2015). Un claro ejemplo pues de intercambio colonial: exportación de productos exóticos (commodities) a cambio de la importación de alimentos y manufacturas.

En Tenerife y Gran Canaria nació el cooperativismo, mediante la figura de los llamados sindicatos agrícolas, como reacción al colonialismo implantado en el comercio del plátano por los ingleses, concretamente por Elders \& Fyffes, que inició la exportación de la fruta canaria al Reino Unido, antes de la I Guerra Mundial. Elders \& Fyffes ejercía un control casi absoluto sobre el comercio del plátano canario. Como apenas tenía competidores que le hicieran frente, se aprovechaba de esas circunstancias para abonar a los cosecheros por su fruta precios relativamente bajos, que no guardaban relación con las altas cotizaciones que obtenía en los mercados ingleses. Además, hacían discriminaciones entre los cosecheros, a los que abonaban precios diferentes que, en algunos casos, no dependían de la calidad de la fruta.

A pesar de la creación de los sindicatos agrícolas locales, la empresa inglesa retomó, después de la crisis provocada por la I Guerra Mundial, sus actividades en las islas, tanto de arrendamiento de tierras a 
la propia terratenencia como en la exportación de la fruta hasta la Guerra Civil, gracias a su dominio del negocio de las navieras y consignatarias y de conocimiento de los mercados británico y europeo. Fue este el primer fracaso del control del comercio exterior de la gran propiedad territorial.

\subsubsection{Segunda etapa (1945-1986): mirando hacia la Península con el franquismo}

Después de la Guerra Civil y la II Guerra Mundial se produjeron grandes cambios en la agricultura canaria en general y, sobre todo, en la de exportación. El intervencionismo (control) estatal de las exportaciones de tomates (S.O.I.V.R.E. ${ }^{6}$ ) y plátanos (C.R.E.P. ${ }^{7}$ ) pasó a ser desde entonces la manera que tuvo el nuevo gobierno fascista de quitar peso a las casas inglesas en la producción y exportación de las commodities canarias. Paralelamente a la recuperación del mercado europeo del tomate, el plátano va a tener paulatinamente en el mercado peninsular su principal destino, tal y como se muestra en la tesis de Rodríguez Brito (1986).

Nuevamente durante este segundo período se llevaron a cabo laboriosas gestiones para convertir en realidad el gran deseo de los agricultores plataneros de poseer una flota propia. En este aspecto, habría que destacar un ambicioso proyecto en conexión con la C.R.E.P. para la creación de una flota canaria. Fue en septiembre de 1954, a raíz de la aprobación por las cortes franquistas de la Ley de Crédito Naval, en virtud de la cual se facilitaban importantes créditos a largo plazo y bajo interés por la Administración para impulsar la construcción de barcos (Periódico Diario de Las Palmas, 16/08/1988). Estos propósitos no se pudieron materializar por la pugna de intereses en juego, pues la aprobación de esa ley franquista iba destinada a subvencionar con créditos blandos y a fondo perdido, a los grandes astilleros y a las grandes navieras españolas que apoyaban al Régimen. De esta manera fracasaba el segundo intento de control del comercio exterior canario por parte de la gran propiedad. Además, esta deriva hacia el control estatal de las divisas y la exportación creciente hacia el mercado peninsular del plátano lo que provoca es el cambio del peso económico-comercial desde Londres a Madrid.

Internamente, sin embargo, los grandes cosecheros sí que obtuvieron un importante logro: la creación y control del crédito agrícola local con la creación de las cajas rurales. El proyecto se convertiría en realidad el 21 de febrero de 1962 con la fundación de la Caja Rural de Santa Cruz de Tenerife ${ }^{8}$. En la misma participaron dieciséis cooperativas, que aglutinaban a 560 socios, y cuatro agricultores particulares, que se vincularon a la entidad antes que las asociaciones a las que pertenecían. Por ello, desde la primera Junta Rectora de la entidad estuvieron representados grandes propietarios de la tierra y el agua de la provincia: Pedro Modesto Campos Rodríguez (presidente; todavía en 1984 aparece como tal), Juan Cullen y Lugo (tesorero), Federico Isidro Sánchez (secretario) y los vocales: Eduardo Gómez Díaz, Pedro Ojeda López, Rafael Marrero Guigou, José González del Carmen, Andrés Hernández Hernández y Emilio Quintana Sánchez (Nuez Yanes, 2007).

Los años sesenta y setenta del pasado siglo pueden considerarse como las décadas doradas de la agricultura de exportación canaria tanto en la expansión de la superficie cultivada como por los beneficios obtenidos en las explotaciones agrícolas. Estas décadas también van a coincidir con la proliferación de nuevas cooperativas y la expansión de las existentes. Buena parte de la responsabilidad de ese crecimiento de la agricultura de exportación la tuvo el Estado a través del INC-IRYDA ${ }^{9}$. El dinero público redujo la inversión inicial (cinco años de carencia del crédito concedido, veinte por ciento del principal a fondo

\footnotetext{
6 Por lo que respecta a los envíos al extranjero, desde mediados de 1936 se incrementó la regulación y, para un control exhaustivo de las divisas que se obtuvieran por las ventas, era necesario obtener la licencia de exportación en el Servicio Oficial de Inspección, Vigilancia y Regulación de las Exportaciones (S.O.I.V.R.E.). La necesidad de divisas que tenía el régimen franquista le llevó a establecer un control administrativo sofisticado y restrictivo de las mismas, desde noviembre de 1936 a través del Comité de Moneda Extranjera, y a partir de 1939 por medio del Instituto Español de Moneda Extranjera (Nuez Yanes, 2007).

7 El 10 de noviembre de 1937 se constituía la Confederación Regional de la Exportación del Plátano (C.R.E.P.), un organismo que, aunque variando de nombre pero no de funciones, regiría las ventas de esta fruta hasta 1993, cuando Canarias entra en la PAC.

8 "Los comienzos de la Caja Rural de Santa Cruz de Tenerife no estuvieron exentos de dificultades, sobre todo para suscribir el capital mínimo necesario para obtener la calificación por parte del Instituto de Crédito Oficial, 5 millones de pesetas. De hecho, tres años después de su creación, y tras sucesivas campañas de captación de aportaciones privadas, tan sólo se habían podido conseguir 460.000 pesetas. La salvación del proyecto se produjo mediante la firma de un acuerdo con el Cabildo Insular de Tenerife por el que este organismo aportaba 4.500.000 pesetas, convirtiéndose así en el principal participe de la institución durante mucho tiempo" (Nuez Yanes, 2007, p. 57).

El Cabildo tinerfeño fue otra de las instituciones tradicionalmente controladas por la terratenencia insular.

9 Instituto Nacional de Colonización sustituido en 1971 por el Instituto Nacional de Reforma y Desarrollo Agrario.
} 
perdido, es decir, 20 de cada 100 euros prestados al agricultor eran regalados, y el resto a bajo tipo de interés), aminorando el riesgo de la misma. Sólo en la provincia de Santa Cruz de Tenerife, se aprobaba ayuda financiera a la sorriba (ayudas a la creación de explotaciones agrícolas) de más de 900 nuevas hectáreas entre 1960 y 1970, lo que equivalía al 50 por ciento de la nueva superficie puesta en producción en esos años (Rodríguez Brito, 1986; Nuez Yanes, 2007).

Junto al apoyo estatal crediticio, la nueva Ley del Régimen Económico y Fiscal (REF) de Canarias de 1972 supuso un aldabonazo a la agricultura de exportación de las Islas, sobre todo, para el cultivo del plátano que recibió enormes ayudas por parte del Estado y cerró las fronteras peninsulares a cualquier plátano que no fuera de origen canario. Ello trajo consigo la generación de nuevas cooperativas plataneras.

En los años setenta se inician procesos de modernización de las explotaciones y de los empaquetados de fruta que provocaron el paulatino descenso de la importancia de los pequeños agricultores y la concentración empresarial: introducción de sistemas de riego que ahorraban agua (aspersión y goteo), instalación de invernaderos, sorribas sobre eriales e improductivos, incorporación de maquinaria moderna tanto a las explotaciones grandes como a los empaquetados, nuevas formas de clasificar y comercializar la fruta.

En resumen, y como en la etapa anterior, este período termina con una crisis agrícola importante que va a afectar a los dos sectores productivos. En la agricultura de exportación del plátano, la demanda del mercado peninsular toca techo ${ }^{10}$. En el sector del tomate, la competencia del Sudeste peninsular y, crecientemente, de Marruecos hacen caer los precios del tomate canario, provocando la desaparición de algunas grandes empresas, pero, sobre todo de pequeños cosecheros de tomates que se agrupaban en torno a las cooperativas (Villalba Moreno, 1978; Rebollo López, 2012).

El tercer cultivo de exportación en orden de importancia, la papa, va a ir perdiendo paulatinamente el mercado británico.

Mientras tanto, la agricultura de mercado interior y de autoabastecimiento iba languideciendo poco a poco, sin ningún incentivo ni apoyo de las instituciones.

La entrada en la Comunidad Europea se planteó entonces como la solución a la nueva crisis del sector primario en las Islas.

\subsubsection{Tercera etapa (1986 a la actualidad): las consecuencias de la entrada en la UE y la globalización}

La adhesión de España a la Comunidad Económica Europea hizo necesaria la actualización del REF y la aprobación de un programa específico para Canarias (POSEICAN) ${ }^{11}$.

Este nuevo marco jurídico ha traído importantes consecuencias para el sector primario de Canarias, tanto para las exportaciones tradicionales (las Organizaciones Comunes de Mercado -OCM- del Plátano y de Frutas y Hortalizas), como para la seguridad alimentaria que afecta a la producción local de alimentos básicos (POSEICAN).

El POSEICAN cuenta con dos capítulos de ayudas económicas fundamentales: uno fomenta la producción local y otro, denominado Régimen Específico de Abastecimiento (REA), subvenciona la importación de determinados productos (lácteos y sus derivados, cárnicos, azúcar, etc.) destinados al consumo directo o a su transformación.

\footnotetext{
10 Hacia 1980 se logró la máxima producción de plátanos en las islas, unas 480.000 toneladas (a finales de los años setenta, Canarias estaba entre los 10 primeros productores de plátanos del mundo), pero a partir de ahí se inicia un descenso que llega hasta las 368.000 en 1992, cuando Canarias entra en la P.A.C. Unas 4.000 has se perdieron en ese período, sobre todo, en pequeñas explotaciones (Nuez Yanes, 2005).

11 Ley 20/1991 de 7 de junio, de modificación de los aspectos fiscales del Régimen Económico Fiscal de Canarias y el Reglamento $1911 / 91$ de 1 de julio de 1991 del Consejo Europeo relativo a la aplicación de las disposiciones del Derecho Comunitario en las Islas, así como en la decisión del Consejo 91/314/CEE, de 26 de junio de 1991, donde se estableció un Programa de Opciones Específicas por la Lejanía y la Insularidad de Canarias (POSEICAN).

En la cumbre de Ámsterdam de 1997, el Consejo aceptó la inclusión en el Tratado Europeo de un artículo (el 299.2) que reconoce la necesidad de establecer medidas especiales para las Regiones Ultraperiféricas (las RUPs: inicialmente Canarias, Madeira, Azores, Martinica, Guadalupe, Guayana Francesa y La Reunión), extremo que también está plasmado en la Disposición Adicional Tercera de la Constitución y en el Estatuto de Autonomía de Canarias.
} 
La comparación entre las ayudas recibidas por la agricultura de exportación como consecuencia de la aprobación del POSEICAN ${ }^{12}$ con las ayudas recibidas a la producción para el mercado local a través del capítulo uno del POSEICAN, resultan bien esclarecedoras, según los datos obtenidos del período 20072013: el $68 \%$ van a parar a los productores de plátanos, el $11 \%$ a los ganaderos, el $7 \%$ a los cosecheros de tomates, el $3 \%$ a los cultivadores de papas, el $2 \%$ al viñedo y el $8 \%$ al resto de la producción vegetal. Es decir, mientras tres cuartas partes de las ayudas van a parar a la tradicional agricultura de exportación, los productos agropecuarios básicos para la alimentación local apenas perciben la otra cuarta parte ${ }^{13}$.

Además, de los 141 millones de euros anuales de ayudas al sector platanero, la mitad va a parar al $5 \%$ de los productores, y el mayor propietario, que controla unas 200 hectáreas de plataneras en el Norte de Gran Canaria, ha recibido casi 4 millones anuales (el triple de dinero que las ayudas comunitarias acaparadas por el ducado de Alba por sus 25.000 hectáreas).

Queda claro entonces que los cultivos dedicados a la agricultura de exportación y la gran propiedad han seguido siendo los grandes beneficiados desde la entrada de Canarias en la Unión Europea. Donde ha ocurrido el cambio, como luego se verá, es en la comercialización de sus productos.

Pero también el análisis de las importaciones vía segundo capítulo del POSEICAN, el REA, ayuda a comprender la situación de la producción local de alimentos: competencia desigual, ruina de sus pequeños y medianos productores y abandono de la actividad. Por ejemplo, un importador de carne refrigerada o mantequilla cobraba 385 euros por tonelada, o 324 euros el queso, cuando el coste de transporte era de 100 euros; así, no resulta extraño que de las 17.000 cabezas de vacuno de ordeño que había en Canarias en 1999 se ha pasado a 7.000 en 2010 (Revista Campo Canario, 2013, 97, pp. 36-37). Subvenciones también importantes registran las importaciones de otros productos cárnicos como aves y cerdo, o cereales, frutas y hortalizas.

La producción vitivinícola en Canarias en la campaña 2012-2013 fue de 9.980 .682 litros. De esta cantidad, 5.351.655 litros no se habían comercializado a 31 de julio de 2014. Estos datos contrastan con los 55 millones de litros de vino que importa el Archipiélago, y que se comercializa en su totalidad lo que demuestra un claro desequilibrio entre producto local e importado. Este subsector cuenta con varias líneas de ayuda del POSEICAN (a la superficie, al embotellado y a la exportación) que cada año alcanza los 3,5 millones de euros (Revista Campo Canario, 2014, 102, pp. 24-25). Es decir, ni siquiera con las ayudas a la producción local el vino puede competir con las importaciones masivas que se realizan a bajo coste desde la Península gracias al REF.

Este tercer período culmina con la crisis actual del sector agropecuario, mostrando que no se han cumplido las expectativas que se prometían para el sector con la entrada en la Comunidad Europea. Como apunta J. S. Nuez:

Desde un par de años antes del cambio de siglo, el sector primario, no solamente perdió importancia relativa en la economía de Canarias, sino que también perdió peso de manera real y efectiva. El Valor Añadido Bruto de esta actividad había continuado creciendo, no al mismo ritmo que el resto de la economía, aunque al menos creciendo, hasta 1997. Pero, si en ese año la aportación era de unos 800 millones de euros, en 2004 solamente alcanzaba los $655^{14}$. No solamente había menos agricultores, sino que el valor de lo que producían era cada vez menor. (Nuez Yanes, 2007, p. 183)

Las cifras económicas se unen a las geográfico-territoriales: el abandono de numerosas explotaciones en todos los cultivos, aunque en menor medida en el plátano. Las islas ya sólo cuentan con unas 40.000 hectáreas cultivadas (de las que casi dos terceras partes corresponden a cuatro cultivos: poco más de 9.000 son plataneras, otras 9.000 de viñedos, 4.000 de papas y 1.600 de tomates), mientras que más de 90.000 hectáreas han sido abandonadas en el último medio siglo (García y Pestana, 2010).

12 A la ficha financiera del plátano proveniente de su OCM, se ha sumado más recientemente una ayuda al transporte para el sector tomatero proveniente de las medidas adicionales del POSEICAN.

13 Las propias cooperativas se han quejado en numerosas ocasiones de estas desigualdades. Sirva de ejemplo lo manifestado por el presidente de la Cooperativa Agrícola Ganadera del municipio de Los Realejos:

El presidente de la cooperativa realejera recalcó que los políticos nacionalistas están contribuyendo a la "ruina" de la agricultura y la ganadería del Archipiélago y favoreciendo la entrada de productos del exterior como la carne y los lácteos, a pesar de que existen diversas iniciativas que propiciarían el auge de estos productos en las islas y reducirían la importación de los mismos. (Periódico La Gaceta de Canarias, 3/03/99)

14530 millones de euros en 2017, lo que representa un descenso del $20 \%$ en algo más de una década. 
Por último, la otra importante conclusión de este tercer período es que los agricultores canarios, incluidos los grandes propietarios, cada vez controlan menos el comercio tanto interior como exterior de sus producciones. Esta afirmación será desarrollada en el siguiente epígrafe dedicado a la evolución del cooperativismo isleño.

Esta breve evolución del sector primario en Canarias permite contextualizar y comprender mejor el papel nada desdeñable de las cooperativas agrarias: ha sido al lado de los cultivos de plátanos, tomates y papas donde las mismas han conocido sus épocas de apogeo y de crisis.

\subsection{Las singularidades de cooperativismo agrario en Canarias}

Existe una amplia experiencia cooperativa en muchos países, y hoy las cooperativas agrarias juegan un papel muy importante en la producción mundial. Parecidas fueron las causas que originaron el cooperativismo en los países desarrollados en el siglo XIX, tanto en EE.UU. y Canadá como en Europa: la lucha contra la gran explotación con trabajo asalariado y la potenciación de la pequeña explotación de carácter familiar (Garrido Herrero, 2003).

Las primeras experiencias cooperativas remiten a Robert Owen, con la Rochdale Equitable Pioneers Society en 1844. Y será a través de Europa (Alemania y Francia), de manera más tardía y con una destacada participación de la Iglesia católica, como el cooperativismo agrario entra en España en los últimos decenios del siglo XIX (Gómez López, 2004a; Martínez Rodríguez, 2005; Martínez Soto, 2005; Basanta Fernández, 2012). Pero históricamente siempre fue un cooperativismo débil y las cooperativas se especializaron por regiones, como el vacuno en Galicia, los cereales en Castilla, el vino en Cataluña y los cítricos en Valencia (Garrido Herrero, 2003). Se puede hablar de más de un siglo de experiencias cooperativas agrarias en España. Desde el punto de vista normativo, las sucesivas leyes de cooperativas reflejan las transformaciones políticas y socioeconómicas del sector primario en el Estado español ${ }^{15}$.

A continuación, se verá cuál fue el proceso singular que siguió el cooperativismo canario en las tres etapas que ya se diferenciaron en la historia agraria contemporánea isleña.

\subsubsection{Primera etapa (1900-1945): los sindicatos agrícolas, la agricultura de exportación y la gran propiedad en los orígenes del cooperativismo canario}

La primera cooperativa inició su andadura cuando la principal compañía inglesa que dominaba la agricultura de exportación en Canarias —Elders \& Fyffes— abandonó el Archipiélago con la Primera Guerra Mundial. Por ello, un grupo de grandes propietarios del Valle de La Orotava (principal comarca platanera de Tenerife) tomó las riendas de los procesos de venta de su fruta, y el 1 de diciembre de 1914 nació el Sindicato Agrícola del Norte de Tenerife (SANT) ${ }^{16}$. Grandes propietarios (en dimensiones canarias) vieron en esta iniciativa la posibilidad de eliminar intermediarios británicos y quedarse con los beneficios de toda la cadena, tanto de producción como comercial. Los fundadores del SANT constituyeron la naviera Tenerife e iniciaron su labor con dos vapores, el Punta Anaga y el Punta Teno. La que pudo ser la primera piedra de la flota propia de los agricultores plataneros, se vio frustrada al ser hundido el Punta Teno en 1917, en el Mar Cantábrico, por un submarino alemán cuando transportaba fruta para el mercado

15 A modo de resumen, sintetizando la bibliografía consultada: Ley de Asociaciones de 1887, Ley de Sindicatos Agrícolas de 30 de enero de 1906 (propició un movimiento asociativo agrario que, promovido y tutelado por las jerarquías de la Iglesia católica en razón de la primera encíclica de la doctrina social de la Iglesia de 1891 por el papa León XII, denominada Rerum novarum), Ley de Cooperativas de 9 de septiembre de 1931 en la II República (supuso un paso fundamental hacia la regularización y democratización del cooperativismo, sin sujeción a un estricto control estatal), Ley de Cooperativas de 1942 del Primer Franquismo (comienza un nuevo y dilatado periodo para el cooperativismo español caracterizado por un férreo control estatal, a través de la Obra Sindical de Cooperación, encuadrada en la todopoderosa Delegación Nacional de Sindicatos), Ley de Cooperativas de 1974 en el Segundo Franquismo (vino a profundizar en la mejora técnica y a perfeccionar la regulación de las sociedades cooperativas y su gestión haciéndolas más abiertas a los cambios que se aproximaban en la España democrática y su incorporación a la Comunidad Europea; de hecho el reglamento se aprobó en 1978), Ley 3/1987, de 2 de abril, General de Cooperativas (Segunda restauración borbónica), Ley de Cooperativas de 27/1999 (España asume la normativa de la UE, pretende adaptar los postulados y principios cooperativistas a las reglas del mercado, a la vez que se descentraliza aún más el corpus legislativo del cooperativismo hacia las Comunidades Autónomas del Estado).

16 Esta entidad (que todavía hoy subsiste con el nombre de FAST) fue fundada por veintitrés agricultores, entre los que se encontraban: don Femando Méndez, don Luis Llarena, don Casiano García, don Miguel Trujillo, don Alberto Chávez, doña Lucía Llarena, doña Isabel Fuentes, don Augusto Méndez, todos apellidos de familias de la gran propiedad en el Valle de La Orotava (Tenerife) (Periódico Diario de Avisos, 30/09/87, p. 2). J. M. Hernández realiza un amplio estudio sobre la evolución de este sindicato en los años 20 y 30 del pasado siglo (Hernández Hernández, 2019). 
inglés. El otro, el Punta Anaga, naufragó en aguas del Puerto de La Cruz (Norte de Tenerife), también en el citado año (Periódico Diario de Las Palmas, 16/08/1988).

Poco a poco los grandes propietarios se decidieron por exportar directamente, incorporándose a los cada vez más numerosos sindicatos del sector. Así, en 1916 se había constituido el Sindicato Agrícola del Este de Tenerife, en 1922 el Sindicato Agrícola del Norte de Gran Canaria y en 1925 el Sindicato Agrícola del Sur de Gran Canaria, entre otros, todos ellos controlados por la terratenencia local.

La causa del nacimiento del poderoso Sindicato Agrícola del Norte de Gran Canaria es similar a la del SANT. Así, las reclamaciones contra el monopolio inglés del propietario del municipio norteño de Guía, Sansó Henríquez, lo llevaron al convencimiento de que no había posibilidad alguna de armonizar los intereses de Fyffes con la de los cosecheros canarios. Por ello, adoptó la única solución viable para liberar del colonialismo económico a que estaba sometido el sector platanero, exportando su propia fruta, para lo que era indispensable la unión de los agricultores. En consecuencia, gracias a la iniciativa de Sansó,

se constituyó el Sindicato Agrícola del Norte de Gran Canaria, entidad que fue acogida con el beneplácito de los agricultores, lo que supuso que el precio al cosechero de los plátanos fuera más en consonancia con el obtenido en los mercados, lo que reportaría ingentes beneficios a la economía platanera". (Periódico Diario de Las Palmas, 16/08/1988)

La verdadera expansión de los sindicatos agrícolas sería en los años treinta, al calor de la crisis del 29 y la competencia del plátano caribeño, de forma que hacia 1935 existían en el sector platanero, además de los ya reseñados, Unión Agrícola de Las Palmas ${ }^{17}$, Unión de Gran Canaria, Bananera de Guía de Gran Canaria, Unión de Agricultores de Arucas, Unión de Cosecheros, Bananera de Tenerife, Sindicato Agrícola del Valle de Güímar, Sindicato Agrícola de San Andrés y Sauces, Sindicato Agrícola de Santa Cruz de La Palma, Sindicato Agrícola del Norte de La Gomera, y Sindicato Corporación de Agricultores de La Palma creado en 1935, formado por los grandes propietarios del municipio de Tazacorte, cuando se vencieron los contratos de arrendamiento que tenían con Elder \& Fyffes. Mientras que en el subsector de exportación del tomate estaban el Sindicato de Productores Tomateros de Tacoronte y Valle Guerra, el Sindicato Tomatero de Fasnia y el Sindicato Tomatero de Adeje (Rodríguez Brito, 1986). Según Román Cervantes, en aquellos años, el $90 \%$ de las exportaciones de productos lo realizaban sindicatos agrícolas (Román Cervantes, 2007).

El crecimiento de los sindicatos agrícolas en ese contexto de crisis generó una lucha con las empresas comercializadoras por la captación de productores. Los primeros pedían la sindicación forzosa, presentándose como salvadores de los pequeños agricultores en manos de los intermediarios fruteros. Pero también es verdad que los sindicatos mantenían una ponderación en la representatividad vinculada a la cantidad de fruta entregada o a la superficie cultivada. Así, tal y como señalan Carnero y Nuez,

la sindicación forzosa era la estrategia de los grandes propietarios ya sindicados para mantener sus márgenes de beneficio en un contexto de caída de precios en los mercados, pues cuanta más fruta pasara por los empaquetados, menores serían los costes gracias a las economías de escala obtenidas. (Carnero Lorenzo y Nuez Yanes, 2015, p. 5)

Por tanto, el nacimiento del cooperativismo canario tiene unas raíces diferentes al del resto de España: es un cooperativismo de comercialización, lo promueve la gran propiedad y está ligado a la agricultura de exportación dominada por agentes foráneos (compañías europeas, principalmente británicas). Además, fracasó en el intento de controlar el comercio exterior canario y utilizó en su beneficio a los pequeños agricultores. Y hay que decir que estas raíces históricas del cooperativismo canario se han mantenido hasta la actualidad, eso sí, profundizándose.

\subsubsection{Segunda etapa (1945-1986): el auge del cooperativismo durante el Franquismo o el intento fracasado de crear una burguesía agraria}

La estrategia autárquica del Primer franquismo estaba en contra del tradicional modelo exportador de la agricultura canaria. Aun así, en 1955 había ya 75 cooperativas en las Islas, pero el verdadero auge

17 La cooperativa Unión Agrícola de Las Palmas, que llegó a ser la segunda entidad exportadora de Gran Canaria, tenía entre sus socios a una buena representación de los terratenientes plataneros locales: Luis Ignacio Manrique de Lara y Llarena, Pedro del Río y Bravo de Laguna, Antonio Suárez Cárdenos, Gonzalo Mayor Alonso, Francisco Aguiar Castellano, Luis Benítez de Lugo y Ascanio, Juan Escudero Arévalo, Melchor Bravo de Laguna y Ponte, Atanasio Díaz Molina y Félix Santiago Melián. (Periódico La Provincia, 1/04/84, p. 13) 
tuvo lugar a partir de los años sesenta (ver Tabla 1). Efectivamente, a la progresiva apertura del régimen se sumó el cambio en la dirección de la UTECO ${ }^{18}$ en la provincia de Santa Cruz de Tenerife. Significativa es la entrevista realizada por J. S. Nuez al Secretario de esa institución, en la que explicaba cómo iban intentando constituir cooperativas en los numerosos municipios donde todavía no existían, pese a la oposición de la terratenencia local (Carnero Lorenzo y Nuez Yanes, 2015). A esa labor de la UTECO se sumó la expansión de la superficie cultivable de regadío con la llegada de las canalizaciones de agua al Sur de la Isla (Martín Martín, 1993). Principalmente en esta comarca, pero también en otras áreas de la Isla, a los grandes propietarios tradicionales se sumó un considerable grupo de emigrantes retornados de Venezuela que invirtieron sus ahorros en la adquisición de predios de mediano tamaño. De nuevo, los mayores propietarios y algunos medianos propiciaron la implantación de cooperativas, copando los puestos directivos y el control de la actividad de las entidades, no en vano también contaban con el beneplácito del régimen (Carnero Lorenzo y Nuez Yanes, 2015).

Efectivamente, según los datos disponibles, obtenidos a veces por encuestas directas, en la década de los sesenta se asiste a un aumento en el número de creación de sociedades, 21 en total, proceso que se mantiene en cifras similares hasta los años ochenta, con 23 (Pérez Artiles, 1991). Y va a ser en este período de expansión de las cooperativas de 1960 a 1980, cuando el fenómeno cooperativista alcanza niveles acordes con el peso relativo de Canarias en el total estatal de los indicadores agrarios (Carnero Lorenzo y Nuez Yanes, 2005).

La estructura del cooperativismo en Canarias tenía, como ocurrió en otros lugares del Estado, un grave problema de tamaño. La dispersión y la fragmentación se ponían de manifiesto cuando para obtener una producción de 420.000 toneladas de plátano se ocupaban más de 12.000 propietarios agrupados en múltiples sociedades. Para solucionar este problema se crea, con buen criterio y como se vio más arriba, una cooperativa de segundo grado denominada COPLACA. La misma se constituyó en Santa Cruz de La Palma el 18 de diciembre de 1970, y en ella se integraron en un primer momento 15 cooperativas ( 8 de Tenerife, 3 de Gran Canaria, 3 de La Palma y 1 de La Gomera) que sumaban un total de 6.000 agricultores, cultivando 3.800 hectáreas de plátanos y con una capacidad de manipulación de 170.000 toneladas. Al año siguiente se inicia la comercialización de la fruta en la Península, y de 1972 a 1974 empiezan a funcionar las plantas de maduración de Madrid, inaugurándose, entre otras, las de Barcelona y Sevilla, con una capacidad de 4.500 toneladas respectivamente (Román Cervantes, 2007). La creación de COPLACA constituía un nuevo intento de controlar el comercio exterior de esta commodity.

Diez años más tarde, el éxito de COPLACA es rotundo. En 1982 con 8.000 asociados y más de 6.000 hectáreas cultivadas, se convierte en la cooperativa agrícola más importante del Estado, llegando a manipular cerca de 200.000 toneladas y con unas ventas que superaron los 14.000 millones de pesetas (más de 84 millones de euros).

Sin embargo, ya a principios de los años ochenta la sobreproducción de plátano, debido a que la demanda del cautivo mercado peninsular toca techo, a la modernización de las explotaciones y al aumento constante de la superficie cultivada, ocasiona una crisis sin precedentes desde la finalización de la II Guerra Mundial. Varias empresas de cosecheros-exportadores y cooperativas de plátanos se enfrentan a una bajada continuada de la producción debido a los bajos precios de la fruta, la mala gestión y corrupción de las instancias directivas. Ejemplos de esta crisis son la destrucción de la mayor empresa de plátanos del Norte de Gran Canaria, Leacock, y, posteriormente, Los Roques y la cooperativa Unión Agrícola de Las Palmas, acaecidas todas ellas al final de esta segunda etapa que se está analizando.

Esta crisis también va a afectar a COPLACA que se fragmenta y pierde la mayor parte de sus establecimientos logísticos en la España peninsular y con ello su poder de comercialización y venta. Esta

18 Los órganos que ejercían el control político de las asociaciones de productores eran las Uniones de Cooperativas del Campo (UTECO). Desde su constitución en 1943 hasta su disolución en 1977, la UTECO de Canarias realizó labores de canalización y distribución de abonos (sobre todo fosfatos de cal), de piensos, de fertilizantes, de combustible y de maquinaria; impulsó las instalaciones de las plantas de maduración de plátanos en la península (labor traspasada luego a la cooperativa de $2^{\circ}$ grado Cooperativa Platanera de Canarias (COPLACA) y negoció la reducción de los aranceles a la exportación de plátanos (Román Cervantes, 2007). 
importante parte del sistema agroexportador canario va pasando a manos de empresas comerciales peninsulares.

En resumen, durante esta segunda etapa, las cosas no cambiaron en demasía. El control de las cooperativas seguía en manos de unos pocos, que no hacían sino perpetuarse en los cargos directivos, como se recoge en los resultados de la encuesta realizada por Pérez Artiles en 1988 (Pérez Artiles, 1991). Sin embargo, a pesar del descenso de la importancia del sector agrario en las Islas en el último cuarto de la centuria pasada, mayor que en el resto del Estado, acentuado por el cambio de modelo económico hacia el turismo en el que van a participar muchos de los grandes propietarios agrícolas, el número de cooperativas se mantuvo.

Las cooperativas seguían siendo un negocio de muchos para pocos. Unos pocos que querían ahora más. De ahí el fomento de la agricultura de exportación en este período, aumentando la producción y los márgenes de comercialización de las cooperativas, mediante la reducción de aranceles para la exportación e importación de insumos agrícolas. Ahora será España o a través de España y no el Reino Unido quien les suministra los inputs industriales para llevar a cabo los cultivos.

Lo nuevo de esta segunda etapa es la progresiva vinculación del comercio exterior —basado en la producción para la exportación de plátanos, tomates y papas- de las producciones agrícolas canarias al mercado peninsular. Para ello, el capitalismo monopolista de Estado va a consolidar como estrategia 1) la intervención en las cooperativas canarias con el objetivo de obtener divisas extranjeras, controlando su tradicional comercio exterior que estaba en manos foráneas, 2) vincular la agricultura de exportación al mercado peninsular, y 3) promocionar el aumento de la superficie de los cultivos de exportación mediante ayuda financiera (cajas rurales y otros bancos, INC-IRYDA) con el objetivo de crear una mediana burguesía agraria y subvencionar a la tradicional terratenencia.

Todo este esfuerzo inversor que provocó el auge de las cooperativas canarias entre los años sesenta y ochenta del pasado siglo se va a echar por tierra en gran medida en la siguiente y última etapa que comienza con la entrada en la Comunidad Europea.

\subsubsection{Tercera etapa (1986 a la actualidad): el regreso de Fyffes y las numerosas y variadas crisis de las cooperativas de tomates y papas}

A la altura del segundo lustro de los ochenta las cooperativas canarias se encontraban en su máximo apogeo en número y actividad, pero en una encrucijada de alternativas debida a los nuevos tiempos sobrevenidos a la actividad agropecuaria.

La evolución de las cooperativas agrícolas hasta hoy ha sido desigual. Sirva de ejemplo la evolución seguida por el sistema cooperativo en la isla de Tenerife (ver Figura 1 y Tabla 1). De 31 cooperativas que existían al comenzar el siglo XXI, el 32 \% tenían como producto principal el plátano, el $26 \%$ papas, $16 \%$ tomates-papas, $10 \%$ tomates, $6 \%$ lácteos y $10 \%$ el resto de productos. En la actualidad siguen abiertas y funcionando de la misma manera unas 17, poco más de la mitad (55\%).

Si se desciende el análisis a su situación según los productos comercializados, actualmente se tiene que el $80 \%$ de las cooperativas de plátanos siguen funcionando, como antes de la última crisis de 2008, de manera normal (solo una ha cerrado y otra se halla en grave crisis). Sin embargo, el resto de las cooperativas no plataneras se hallan en franca crisis. Así, de un total de 8 cooperativas de papas, solamente un 50 \% está funcionando de manera más o menos normal (mientras que una está cerrada, una en quiebra y absorbida y dos en crisis grave). De las cooperativas mixtas de producción de tomates-papas, queda una en normal funcionamiento (dos en crisis grave y dos cerradas), es decir, sólo un $20 \%$. Ninguna de las tres cooperativas de tomates funcionan normalmente (dos comercializan bajo mínimos y una cerró). Finalmente de las dos de lácteos, una cerró definitivamente. En resumen, sólo las cooperativas de plátanos han logrado sobrevivir de manera holgada, mientras que han disminuido en menos de la mitad las dedicadas a tomates, papas y ganadería, otras se encuentran funcionando con grandes dificultades, en proceso de quiebra y cierre definitivo. ¿Cómo se ha llegado a la situación actual descrita? 
Tabla 1. Listado y estado actual de las cooperativas de la isla de Tenerife

\begin{tabular}{|c|c|c|c|c|c|c|}
\hline NOMBRE COOPERATIVA & $\begin{array}{l}\text { PRODUCTO } \\
\text { PRINCIPAL }\end{array}$ & COMARCA & $\begin{array}{l}\text { LOCALIZACIÓN } \\
\text { GEOGRÁFICA }\end{array}$ & MUNICIPIO & FUNDACIÓN & ESTADO ACTUAL \\
\hline 1. COISBA ( Cooperativa Agrícola Isla Baja ) & Plátano & Ycoden - Daute & Litoral de barlovento & Buenavista & 1965 & Abierta \\
\hline 2. Cooperativa Agrícola Icod de los Trigos (Icod El Alto) & Papas & Ycoden - Daute & Medianías de barlovento & Los Realejos & 1998 & Abierta \\
\hline 3. Cooperativa Agrícola Rambla & Plátano & Ycoden - Daute & Litoral de barlovento & $\begin{array}{l}\text { San Juan de } \\
\text { la Rambla }\end{array}$ & $1945 i ?$ & Abierta \\
\hline 4. Sociedad Cooperativa Agrícola Las Medianías & Papas & Ycoden - Daute & Medianías de barlovento & $\begin{array}{l}\text { San Juan de } \\
\text { la Rambla }\end{array}$ & 1998 & Abierta, crisis después de 2008 \\
\hline 5. Sociedad Cooperativa Hortofrutícola Vistas de Icod & $\begin{array}{l}\text { Frutas } \\
\text { y hortalizas }\end{array}$ & Ycoden - Daute & Medianías de barlovento & $\begin{array}{l}\text { Icod de los } \\
\text { Vinos }\end{array}$ & 2000 & Abierta \\
\hline 6. Cooperativa Agrícola Fuentes de La Guancha & Papas & Ycoden - Daute & Medianías de barlovento & La Guancha & & Cerrada antes de 2008 \\
\hline 7. Cooperativa Agrícola del Norte de Tenerife (FAST) & Plátano & Valle de La Orotava & Litoral de barlovento & La Orotava & 1914 & Abierta \\
\hline 8. Cooperativa Agrícola Bananera de Tenerife & Plátano & Valle de La Orotava & Litoral de barlovento & $\begin{array}{l}\text { Puerto de la } \\
\text { Cruz }\end{array}$ & 1932 & Abierta \\
\hline 9. Quesería de Benijos & Lácteos & Valle de La Orotava & Medianías de barlovento & La Orotava & 1998 & Abierta \\
\hline 10. Cooperativa Agrícola y Ganadera de Benijos & Papas & Valle de La Orotava & Medianías de barlovento & La Orotava & 1996 & $\begin{array}{l}\text { Absorción por deudas por el Cabildo de Tenerife } \\
\text { después de 2008. Gestionada por la APFH Garañana }\end{array}$ \\
\hline 11. Cooperativa Agrícola Ganadera Villa de Los Realejos & Papas & Valle de La Orotava & Medianías de barlovento & Los Realejos & 1998 & Abierta \\
\hline 12. Cooperativa del Campo la Candelaria & Ganadería & Área metropolitana & Medianías de barlovento & La Laguna & 1951 & Abierta, venta de fábrica de piensos por crisis de 2008 \\
\hline $\begin{array}{l}\text { 13. COAGATE (Cooperativa de Agricultores y Ganaderos } \\
\text { de Tenerife }\end{array}$ & Papas & Área metropolitana & Medianías de barlovento & La Laguna & & Abierta, escasa actividad \\
\hline 14. Cooperativa Agrícola Cosecheros de Tejina & Plátano & Área metropolitana & Litoral de barlovento & La Laguna & 1947 & Cerrada después de 2008 \\
\hline 15. Cooperativa Agrícola Ganadera Los Panascos & Papas & Área metropolitana & Medianías de barlovento & El Rosario & 2001 & Abierta \\
\hline
\end{tabular}




\begin{tabular}{|c|c|c|c|c|c|c|}
\hline 16. Cooperativa agrícola Sur de Tenerife de Güímar & Plátano & Valle de Güímar & Litoral de sotavento & Güímar & & Cerrada antes de 2008 \\
\hline 17. CASI (Cooperativa Agrícola San Isidro) & Tomate-papas & Abona - Chasna & Medianías de sotavento & Granadilla & 1957 & Abierta \\
\hline $\begin{array}{l}\text { 18. COCARMEN (Cooperativa Agrícola Nuestra Señora } \\
\text { del Carmen) }\end{array}$ & Tomate-papas & Abona - Chasna & Medianías de sotavento & Granadilla & 1967 & Cerrada después de 2008 \\
\hline 19. CASMI (Cooperativa Agrícola San Miguel) & Papas & Abona - Chasna & Medianías de sotavento & San Miguel & 1959 & Abierta \\
\hline $\begin{array}{l}\text { 20. COSLO (Cooperativa Agrícola del Campo San } \\
\text { Lorenzo) }\end{array}$ & Plátano & Abona - Chasna & Litoral de sotavento & Arona & 1952 & Abierta, crisis desde 2008 \\
\hline $\begin{array}{l}\text { 21. COPLACSIL (Cooperativa Platanera de Costa del } \\
\text { Silencio) }\end{array}$ & Plátano & Abona - Chasna & Litoral de sotavento & Arona & 1985 & Abierta \\
\hline 22. Sociedad Cooperativa Cumbres de Abona & Vino & Abona - Chasna & Medianías de sotavento & Arico & 1989 & Abierta \\
\hline 23. Quesería de Arico Sociedad Cooperativa & Lácteos & Abona - Chasna & Litoral de sotavento & Arico & $2003 i ?$ & Cerrada después de 2008 \\
\hline 24. Cooperativa Agrícola Nuestra Señora de Abona & Tomate-papas & Abona - Chasna & Medianías de sotavento & Arico & 1964 & Cerrada después de 2008 \\
\hline 25. Cooperativa Agrícola Los Roques & Tomate-papas & Abona - Chasna & Medianías de sotavento & Fasnia & 1961 & Prácticamente sin actividad desde 2008 \\
\hline 26. Cooperativa El Calvario & Tomate-papas & Abona - Chasna & Medianías de sotavento & Güímar & 1968 & Abierta, prácticamente sin actividad desde 2008 \\
\hline 27. COAGISORA (Cooperativa Agrícola de Guía de Isora) & Tomate & Isora & Medianías de sotavento & Guía de Isora & 1965 & Abierta, gran disminución de su actividad desde 2008 \\
\hline 28. Cooperativa Agrícola Nuestra Señora de la Paz & Tomate & Isora & Medianías de sotavento & Guía de Isora & 1966 & Abierta, gran disminución de su actividad desde 2008 \\
\hline 29. Cooperativa Agrícola Punta Blanca & Plátano & Isora & Litoral de sotavento & Guía de Isora & 1967 & Abierta \\
\hline 30. Cooperativa Agrícola San Sebastián & Plátano & Isora & Litoral de sotavento & Adeje & 1978 & Abierta \\
\hline 31. Cooperativa Agrícola Tamaimo & Tomate & Isora & Medianías de sotavento & $\begin{array}{l}\text { Santiago del } \\
\text { Teide }\end{array}$ & 1965 & Cerrada después de 2008, venta de inmuebles \\
\hline
\end{tabular}

Litoral de barlovento (norte expuesto a los vientos húmedos del alisio) y sotavento (sur árido) es la franja comprendida entre 0-300 metros (en ella se localizan los cultivos de plátanos y tomates), mientras que el término medianías en Canarias hace referencia a la franja situada entre el área litoral anterior y la zona boscosa de cumbres, aproximadamente entre los $300-1500$ metros (en ellas se localizan los cultivos de papas). 
Figura 1. Distribución de las cooperativas agropecuarias en la isla de Tenerife según sus producciones principales y en relación a la localización de los cultivos

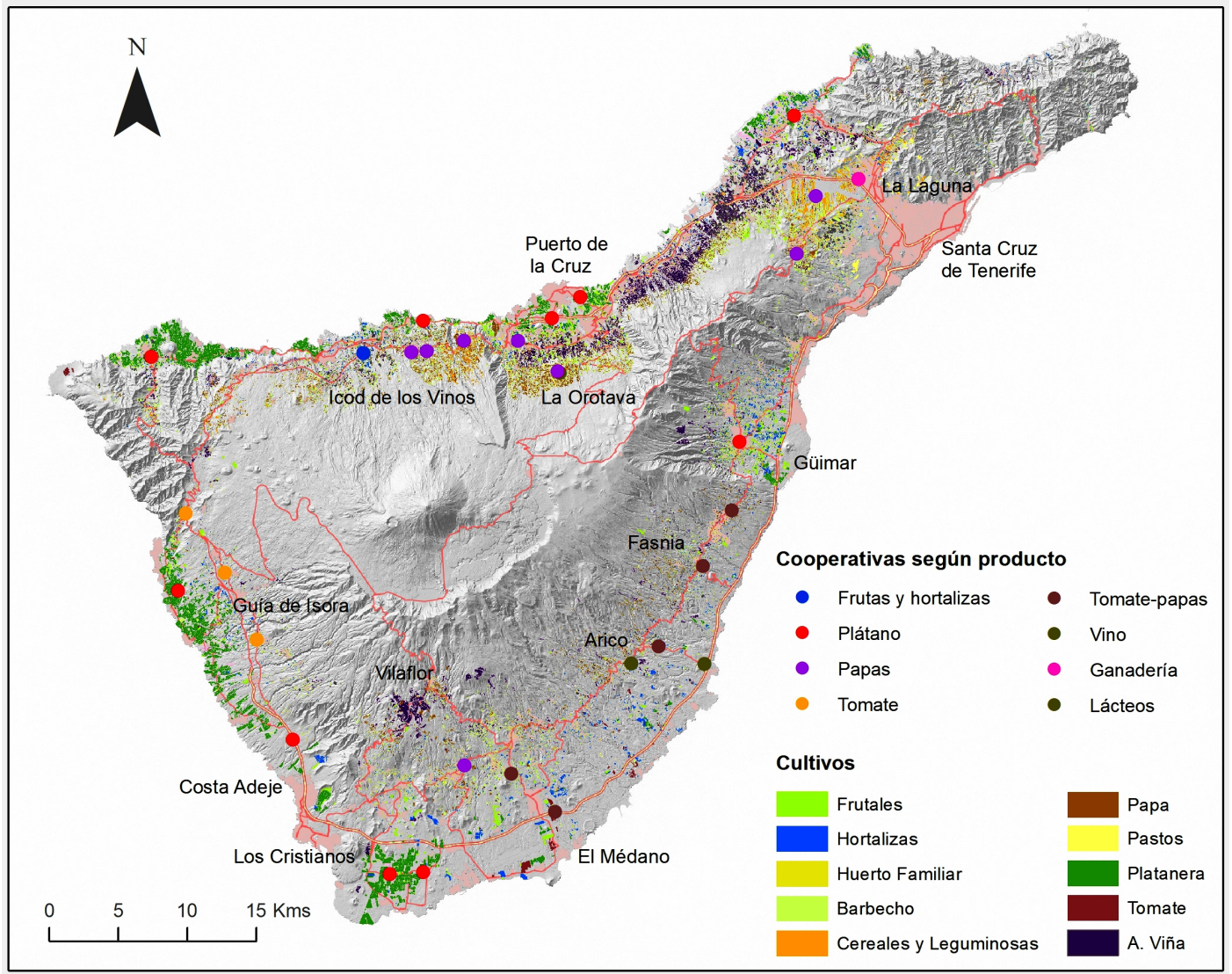

Fuente: Mapa de Cultivos de Tenerife de 2016 (https://www. gobiernodecanarias.org /agricultura/temas/mapa_cultivos/). Elaboración propia

Una alternativa a la crisis de los tradicionales cultivos de exportación por parte de las cooperativas está siendo la reorientación productiva hacia otros cultivos para exportar y, sobre todo, para el mercado interior. Pero aquí se encuentran también con las importaciones masivas de esos mismos productos, muchos de los cuales vienen con algún tipo de subvención. El presidente de una de las principales cooperativas de tomates de Tenerife, Coagrisora, lo expresaba así:

Delgado opina que hay un potencial "enorme de poder crecer en frutas y hortalizas", pero hay "ciertos problemas", pues "en parte las administraciones públicas deben actuar en el sentido de no premiar esas importaciones en detrimento de lo de aquí, porque reciben unas ayudas adicionales, y eso perjudica enormemente a las producciones propias. (Periódico Diario de Avisos, 18/03/2013)

Respecto al subsector exportador, la evolución seguida por las cooperativas plataneras se hace más compleja con la entrada en la Comunidad Europea. A finales de los años ochenta, las cooperativas Cosecheros de Tejina, Coplacsil y Coslo (Tenerife), Costa Caleta (Gran Canaria) o Copalma (La Palma) se daban de baja de COPLACA, como en otras ocasiones, por discrepancias con la dirección de la cooperativa de segundo grado y por lo que consideraban como deficiente gestión comercial, comenzando a exportar de nuevo de manera independiente. La fruta comercializada por COPLACA había pasado de 186.000 toneladas en 1981 (41 \% de la producción canaria) a 145.000 en 1983 (32\%), y a finales de 1987 a unas 90.000 (20 \%) (Nuez Yanes, 2007). Durante esa década la comercialización pasó de manos canarias —a través de COPLACA - a manos de empresas peninsulares ${ }^{19}$ que aprovecharon esas discrepancias y la división de los productores plataneros locales.

19 Conocido es por todos que estas empresas peninsulares son maduradoras y constituyen el eslabón intermedio principal en la cadena de comercialización, ya que, en la mayoría de los casos, el productor canario (empresa o cooperativa) entrega la fruta a un madurador que luego efectúa la venta a un supermercado o distribuye en el mercado mayorista (ver Cáceres-Hernández, Martín Rodríguez, González Gómez y Nuez Yánez, 2013). 
Con la entrada de España en la PAC en 1986 y de Canarias unos años después (1991), ya que inicialmente se había aprobado su no integración, las cooperativas atisbaron una tabla de salvación.

Como consecuencia de la entrada de Canarias en la PAC, en el Archipiélago son de aplicación tres tipos de organizaciones de productores: una general para todo el territorio comunitario, las de frutas y hortalizas, y dos específicas, las organizaciones de productores de plátanos (OPPs) y las agrupaciones de productores ganaderos. En esta nueva coyuntura, las cooperativas van a jugar un papel de primer orden en estas organizaciones de productores comunitarias.

Las 61 entidades de comercialización de plátanos se convirtieron en 24, y a partir de 2003 en 6. Todas integradas a la Asociación de Organizadores de Productores de Plátano de Canarias (ASPROCAN), siguiendo las recomendaciones de la normativa comunitaria al respecto. No obstante, sigue imperando la idea del minifundio comercializador, y lo único que motivó esta mayor concentración fue el ahorro derivado de las economías de escala.

Aunque todas las cooperativas plataneras estuviesen integradas en las OPPs, muy pronto comienzan a variar sus estrategias comercializadoras para ampliar y/o afianzar su participación en la distribución, ya que el mercado no se circunscribía a la península y Baleares. Quizás la más relevante fue la creación de Eurobanancanarias S.A. en 1993 al 50 por ciento entre COPLACA y la multinacional irlandesa Fyffes ${ }^{20}$. Se renuncia pues a la idea de crear un gran grupo canario que dominara todas las fases del plátano (desde la producción hasta la venta), argumentando que dicha asociación se llevaba a cabo para combatir con mayor efectividad a las grandes multinacionales americanas. Era el regreso de Fyffes medio siglo después. Casi con "lágrimas en los ojos", el defensor de las cooperativas Wladimiro Rodríguez (platanero y profesor jubilado del Departamento de Geografía e Historia de la Universidad de La Laguna), reconocía el fracaso en la creación de un gran operador propiamente canario en el mercado del plátano ${ }^{21}$.

Nuez y Carnero no vieron aquí la transcendencia histórica del acuerdo COPLACA-Fyffes, y cuando analizan el mismo presentan la perspectiva del economista que no ve más allá de rentabilidad y beneficios empresariales:

Si, por un lado, esta participación ha permitido a Fyffes controlar la comercialización de buena parte de la producción platanera de las Islas, y aprovechar la red que ya tenía establecida en la Península la entidad canaria para colocar en el mercado español las producciones obtenidas en sus explotaciones latinoamericanas; por otro, ha permitido que los productores integrados en Coplaca ${ }^{22}$ participen al máximo en la cadena de distribución, que liguen su destino a uno de los principales grupos comercializadores en Europa y que diversifiquen sus fuentes de ingresos mediante la intermediación en otros productos hortofrutícolas. Así, Eurobanancanarias se ha hecho con el 70 por ciento de Ángel Rey, S.A. - una de las más importantes empresas en España dedicadas a la distribución hortofrutícola-, con el control de Fruites D’or en Mallorca, Frutas Iru en el País Vasco y, recientemente, Morales e Hijos en Barcelona, que complementan las instalaciones que posee en Jerez, Sevilla, Vigo, Murcia y Alicante ${ }^{23}$. (Nuez Yanes y Carnero Lorenzo, 2005b, p. 227).

¿Cuál ha sido la evolución desde entonces?

En 2018 la multinacional norteamericana Dole Food Company entra en la compañía Total Produce, de la que forma parte Eurobanan y en la que se encuentra COPLACA-Fyffes, dando lugar a la mayor

20 Así lo explica el gran propietario tinerfeño y director general de COPLACA, Leopoldo Cólogan, en una entrevista concedida al periódico La Opinión de Tenerife, en julio de 2006:

..A nivel externo, es conocida nuestra lucha con Estados Unidos y las multinacionales. En ese momento, yo planteé a la organización de productores de Coplaca la necesidad de prepararnos para los peores momentos. Eso nos llevó a buscar un socio y a constituir una empresa, el Grupo Eurobanan. [...] En el cierre del año pasado, en una facturación de alrededor de cincuenta mil millones de pesetas [300 millones de euros]. Nos hemos convertido en el primer grupo de maduración de plátanos y comercialización de otras frutas líderes en España.

La crisis de los años ochenta del pasado siglo hizo que COPLACA dejara de ser la cooperativa de segundo grado que comercializaba la mayor parte del plátano. Aun así, sigue siendo la mayor de todas las organizaciones de productores.

21 Entrevista a Wladimiro Rodríguez Brito (24 de enero 2020).

22 COPLACA que, con más del $35 \%$ de la producción canaria de plátanos, agrupa a 4.500 agricultores de 15 cooperativas en Tenerife, La Palma, Gran Canaria, El Hierro y La Gomera. Es la mayor organización de productores de la UE con una superficie de cultivo de más de 3.500 hectáreas (http://www.eurobanan.com/index.php?pagina=accionistas.

23 Otros casos similares, aunque de menor dimensión comercializadora y posteriores en el tiempo, han sido los casos de las constituciones de Penca 2000 y Platania (Nuez y Carnero, 2005b). 
empresa de banano del mundo ${ }^{24}$. Esta noticia ha sido el epílogo de tres fenómenos que se han venido produciendo en el sector del plátano en los últimos años.

En primer lugar, la cuota de mercado peninsular del plátano se ha ido reduciendo, mientras crecía la del plátano extranjero. Diversas noticias sitúan el porcentaje medio en un $65 \%$ de las ventas para el plátano canario frente al $35 \%$ para el importado. Pero ha habido años recientes, como sucedió en 2018 y 2019 , en la que la cuota de mercado del plátano importado ha oscilado entre el 48 y el $58 \%{ }^{25}$.

En segundo lugar, la producción de plátanos se concentró en cada vez menos manos. Actualmente producen plátanos en Canarias unos 8.000 agricultores (la gran mayoría de ellos agrupados en cooperativas), pues resulta que apenas 300 reciben el $50 \%$ de las ayudas compensatorias por pérdida de renta. Por el camino, en estas primeras décadas del siglo XXI se han quedado las tres cuartas partes de los pequeños agricultores o familias, pues se ha pasado de 10.000 a esos 2.500 , como señala un reciente trabajo de Nuez Yanes (2017).

Por último, el lobby canario del plátano ASPROCAN se fractura en pedazos: Leopoldo Cólogan (COPLACA) pierde su dominio secular al romper con el primer productor de plátanos de Canarias, Félix Santiago (Cupalma de La Palma y Plátanos de Canarias de Gran Canaria) ${ }^{26}$.

Todos estos cambios producidos en el proceso de globalización del comercio mundial del plátano, en general, y en Canarias, en particular, han supuesto enormes cambios para el productor directo. Del precio final que paga el consumidor por el plátano canario, el agricultor recibe de media 0,45€ por kilo ( $25 \%)$, la cooperativa $0,11 €(6 \%)$, el madurador-intermediario $1,06 €(60 \%)$ y la tienda (9\%); es decir, hasta un $235 \%$ más que lo recibido por el agricultor va a parar a las multinacionales maduradoras. Algo menos de un tercio del negocio del plátano queda en Canarias, pero para ello hay que dedicar las mejores tierras (una cuarta parte de la superficie cultivada actual) y mejores aguas (casi la mitad del agua consumida).

Las cooperativas, principalmente las tomateras, y hasta las empresas privadas y SATs, después de un siglo de exportaciones canarias al mercado europeo (Londres y Rotterdam), han sufrido una crisis que casi ha acabado con el sector. Y las que quedan en pie trabajan a duras penas, pues han perdido socios o se encuentran gravemente endeudadas. Entre las causas más importantes de esta situación, además de las plagas $^{27}$ importadas que han afectado a la disminución de la productividad de los cultivos, se encuentran la competencia del tomate marroquí en precios y mano de obra y los altos costes de las inversiones en la modernización de las explotaciones canarias. Ello se ha traducido, unido a los bajos precios obtenidos, en un endeudamiento del sector que ha provocado la quiebra de numerosas cooperativas y empresas privadas.

La más importante comarca tomatera de Canarias, el Sureste de Gran Canaria, perdió en los primeros quince años del siglo actual seis de sus ocho cooperativas de tomate: San Rafael de Vecindario que tras una crisis a principios de este siglo terminó cerrando hace cinco, Cooperativa Limitada del Campo (Colicam) fundada en 1979, Sociedad Cooperativa Molino Blanco del Doctoral (Moblandoc), Cruce de Sardina, Cooperativa La Orilla domiciliada en Pozo Izquierdo y también desapareció la sociedad Valerón. Sólo sobreviven la pionera, Counaga, fundada en 1964, y Yeoward, fundada en $1984^{28}$. La única cooperativa de Fuerteventura, dedicada a la exportación de tomates, se quedaba con solo 40 socios en 2012, después de años de malas zafras que provocaban tirar los tomates debido a la competencia de Marruecos o Almería y los bajos precios.

En la comarca tomatera del Sur de Tenerife terminó cerrando la cooperativa Nuestra Señora del Carmen-Cocarmen (Granadilla de Abona y Vilaflor), que fue una de las cooperativas de tomates, papas, pimientos y plátanos más potentes y modernas de la Isla, llegando a exportar más de 12 millones de kilos de tomates, con más de 500 socios y un centenar de empleados. Cesó su actividad en 2009 agobiada por deudas de más de 9 millones de euros desde 2007, sometida a un concurso de acreedores, expedientes de

24 https://ec.europa.eu: Case M.8829 - Total Produce / Dole Food Company - European Commission.

25 Periódico digital El Diario, 7/02/2020: https://www.eldiario.es/Canariasahora /agricola /agricultura /banana-encima-plátano-canarioPeninsula_0_992851672.html. Y la noticia incluso se queda corta pues en un trabajo reciente sitúa la media de la cuota de mercado en Península y Baleares del plátano canario entre un 51,5 \% y un 64,8 \% (Luis Rodríguez, Luis Vega y Suárez López, 2018). 26 https://espiral21.com/asprocan- se-desangra-la- crisis-las-elites- controlan -las- ayudas- plataneras/.

27 Entre otras, las dos más importantes han sido: la plaga de la Mosca Blanca en los años noventa del pasado siglo y en la primera década del XXI; y la polilla Tuta Absoluta, originaria del norte de Sudamérica, muy extendida en la segunda década del siglo XXI.

28 Fuente: Periódico La Provincia/Diario de Las Palmas, 12/10/2015, p. 10. Para Fuerteventura: Periódicos Canarias 7, marzo de 2012, p. 7 y La Provincia: 7/03/2008, p. 14. 
regulación de empleo, despidos improcedentes, huelgas de sus trabajadores, posible corrupción de sus órganos de dirección, etc. Todavía en 2010 y 2011 las instituciones públicas locales intentaron salvarla, pero fue en vano ${ }^{29}$. También quebró en el Sur de Tenerife la cooperativa Nuestra Señora de Abona (Arico), que llegó a tener en los años noventa del pasado siglo 620 socios agricultores y a exportar 2,8 millones de kilos de tomates y 50 empleados. Su deuda ascendía a 4,5 millones de euros, y, por esto, tuvo que llevar a cabo una regulación de empleo y entró en concurso de acreedores, hasta que se vio obligada a cerrar en el año $2014^{30}$.

La cooperativa de tomates más importante de Tenerife, Coagrisora, pasó de exportar 36 millones de kilos en el año 1998, a solo un millón en 2013 (Periódico Diario de Avisos, 18/03/2013, p. 13).

En lo que se refiere al tercer cultivo importante de las Islas, la papa, se debe decir que las cooperativas Nuestra Señora de Abona y Cocarmen, citadas anteriormente como dedicadas al tomate, también exportaron cantidades importantes de papas. El cierre de ambas afectó a sus socios. Otras cooperativas propiamente de papas, que habían sido creadas en los años noventa del pasado siglo en el Norte de Tenerife, entraron en procedimientos concursales debido a su alta deuda, como es el caso de la cooperativa Las Medianías (San Juan de la Rambla) en año 2012 (Periódico El Día, 14/02/2012, p. 43).

El caso de quiebra más importante de una cooperativa de papas fue Benijos en las medianías del Norte de Tenerife (La Orotava) ${ }^{31}$. Esta cooperativa llegó a tener una deuda de 4,5 millones de euros con las entidades financieras, lo que provocó despidos improcedentes, concurso de acreedores, manifestaciones, impagos de las producciones entregadas por los socios, etc. Finalmente, el Cabildo Insular hizo frente a la deuda financiera para salvar las instalaciones de la cooperativa, pero haciendo pasar la gestión de la misma a la entidad Garañaña dependiente de la cooperativa sureña Casmi ${ }^{32}$.

Por último, la crisis de 2008 golpeó a las cooperativas ganaderas. La propia cooperativa de Benijos que sufrió la quiebra también era ganadera. La mayor cooperativa ganadera de Canarias con sede en el municipio tinerfeño de La Laguna, Cooperativa del Campo La Candelaria, se vio obligada a vender su fábrica de piensos para hacer frente a la elevada deuda contraída, levantada con inversión de fondos públicos, a una empresa privada (Cereales Archipiélago) (Periódico Diario de Avisos, 5/10/14). Y una de ellas, la cooperativa Quesería de Arico, quebró ante la enorme deuda contraída con una entidad bancaria local para la construcción de sus instalaciones y el no pago durante meses a los ganaderos de cabras de la leche entregada a la cooperativa ${ }^{33}$.

Otras entidades asociativas ganaderas, como la Cooperativa de Ganaderos de El Hierro están enormemente mermadas en cuanto a su potente pasado cercano. Cuando se creó en 1989, eran 700 ganaderos, la mayoría de los productores de leche de la isla y en 2015 quedaban poco más de 30. Se producían 15.000 litros de leche al día, ahora apenas 2.000. La situación de la cooperativa empeoró a partir de la campaña 2010-2011 (Revista Campo Canario, 2015, 105, pp. 16-17).

Ha sido gracias a la reorientación de las producciones (tubérculos, cereales, carne y lácteos, a las que se suman en los últimos años las hortalizas y frutas) de los socios de estas cooperativas al mercado interior insular y regional, que las mismas han evitado el cierre a partir de la crisis económica de 2008. Aun así, la facturación ha disminuido notablemente y, además, las cooperativas han perdido numerosos socios. Menos producción y un menor número de socios, porque, entre otros motivos, en este mercado regional deben competir con las importaciones de esos mismos productos que llegan subvencionados o con mínima tributación a Canarias y/o con el cuasi monopolio de las grandes cadenas de supermercados. Sirva de ejemplo la firma de acuerdos entre grandes cadenas y cooperativas agrícolas locales que están condicionando, cuando no subordinando, la independencia de estas últimas (acuerdo con Makro para el suministro de frutas y hortalizas en 2014, con Mercadona para papas en 2013, con Alcampo y con Carrefour).

\footnotetext{
29 Fuente: prensa periódica sobre CoCarmen La Opinión de Tenerife, 29/11/2007, p. 10; 30/11/2007, p. 10; 1/12/2007, p. 12 y 10/12/2007, p. 6; Diario de Avisos, 15/03/2010, p. 7 y El Día, 15/02/2011, p. 16. Sobre Nuestra Señora de Abona: Periódico La Opinión de Tenerife, 9/12/2013, p. 9.

30 Fuente: Periódico La Opinión de Tenerife, 9/12/2013, p. 9.

31 Periódico Diario de Avisos, 7/8/2010, p 8; 9/08/2012, p. 7; 7/12/2012, p. 8; El Día, 10/06/2013, p. 9.

32 Entrevista a Ángela Delgado, Presidenta de ASAGA-Canarias y de la cooperativa LACASMI del Sur de Tenerife (8 de julio de 2020 ).

33 Fuente: Periódico Canarias7, 29/08/2008: https://www.canarias7.es/hemeroteca/las_deudas_ahogan_en_siete_meses_la_queseria_de_ arico-KDCSN107418
} 


\section{Discusión de resultados}

Esta investigación corrobora algunas de las conclusiones obtenidas por otros trabajos de investigación ya publicados y cuyas referencias han sido señaladas en su epígrafe respectivo. Al menos destacan tres con las que se está de acuerdo.

La primera es que la estructura de las cooperativas se ha caracterizado por la orientación comercializadora de su actividad.

En segundo lugar, las iniciativas colectivas no tuvieron entre los pequeños propietarios una elevada aceptación, pero no por su individualismo y recelo como afirma Román Cervantes (Román Cervantes, 2007), sino más bien por el papel dirigente que tuvieron los grandes propietarios en su creación y, en consecuencia, el menor poder de decisión de los primeros. No obstante, sí se corrobora que cientos de estos pequeños propietarios se hicieron socios de cooperativas. Por tanto, los pequeños propietarios entendieron que era necesario asociarse para poder hacer frente a la comercialización de sus producciones.

Por último, queda también claro y evidente que las cooperativas fueron un producto de las iniciativas de los representantes de la gran propiedad agroexportadora isleña, que poseían los recursos productivos esenciales, las mejores tierras y el agua.

Resulta discutible, sin embargo, la afirmación de que el asociacionismo canario se haya distinguido por su escasa incidencia en la mejora del nivel de renta de la mayoría de los agricultores. Aquí es necesaria una mayor evidencia empírica, ya que con los trabajos hasta ahora realizados no se puede concluir dicha afirmación.

Respecto a la discusión aportada en este artículo se debe señalar que el dominio de los grandes propietarios en las cooperativas se ha hecho más complejo en la última atapa de la historia de las cooperativas (de 1986 a la actualidad). Además, si se considera que el sector exportador canario se vincula a las cooperativas como un ejemplo de commodity, resulta mejor interpretable con el concepto del carácter colonial de Canarias. La crisis de las cooperativas se inicia con la contracción del mercado exterior a sus producciones, y se acentúa con el intento de reconducir sus producciones hacia el mercado interior en dura lucha con el sistema de importación de alimentos. En este sentido, no se puede entender las entidades asociativas de Canarias sin su vinculación a los agentes comerciales que intermedian la producción agropecuaria que intenta abastecer al mercado isleño. El control del aparato del Estado con su desarrollo normativo refrenda la anterior afirmación.

Futuras investigaciones sobre el cooperativismo canario deberían aportar luz a lo acontecido con los pequeños agricultores cooperativistas, tanto desde el punto de vista positivo, en la generación de una burguesía agraria de carácter familiar o empresarial, como negativo, en la desaparición de ese tipo de explotaciones como consecuencia de las sucesivas crisis de las cooperativas. Otra línea de investigación que se cree importante para desarrollar sería, dada las importantes aportaciones de dinero público a las mismas, las conexiones entre el poder político, el empresarial (entidades bancarias, por ejemplo) y las juntas rectoras de las cooperativas en manos o dependientes de la gran propiedad (¿caciquismo?), frente a la mayoría de los socios.

\section{Conclusiones}

Con la entrada en el siglo XXI, y sobre todo en los últimos años, en relación directa con la pérdida de peso del sector agropecuario en las Islas y la creciente terciarización de la economía vinculada al fenómeno turístico, el movimiento cooperativo se ha estancado e incluso desciende, como lo muestra el hecho de la crisis y posterior cierre de varias entidades cooperativas históricas en la isla de Tenerife o de Gran Canaria. Entre los antecedentes y causas de dicha crisis estarían los impagos a los cooperativistas, la corrupción de sus dirigentes, su endeudamiento, los embargos por hipotecas y/o pérdida de la propiedad de las explotaciones de los socios, abandono de los mismos de las cooperativas cayendo nuevamente en manos de los intermediarios, envejecimiento y falta de relevo generacional, abandono de las explotaciones o dedicación de las mismas a la urbanización turística y/o residencial, etc.

Aparte de que el cooperativismo canario es una singularidad dentro del cooperativismo en el Estado español, la aportación en este artículo a lo ya publicado hasta el momento se ha centrado en los siguientes aspectos. 
El dominio de los grandes propietarios en las cooperativas se ha hecho más complejo en la última atapa de la historia de las cooperativas. A las históricas familias latifundistas se han unido grandes empresarios de la construcción y/o servicios que han visto en el sector agrario ganancias seguras y subvenciones comunitarias a partir de los años noventa cuando Canarias entra en la PAC de la Unión Europea: ejemplos de Félix Santiago en el Norte de Gran Canaria, la familia Rosa en Lanzarote, Indalecio Pérez y Tomás Toledo en el Sur de Tenerife, Antonio Plasencia -dueño de la Promotora Punta Larga- en el Valle de Güímar). Este dominio de la gran propiedad rentista en el sistema cooperativo explica tanto la escasa dimensión del movimiento cooperativo en Canarias como la crisis de las cooperativas (mala gestión, corrupción $^{34}$, endeudamiento, cierres...). Sirva de ejemplo el sector del plátano que partía de 10.000 pequeños productores cuando se aprueba su OCM para pedir la ayuda compensatoria, y han quedado actualmente unos 2.500 (Nuez Yanes, 2017).

El lobby de la commodity del plátano es el mejor ejemplo del mantenimiento del carácter colonial de Canarias en el sector de la exportación. Algunos investigadores señalan que uno de los problemas del sector del plátano es que, a pesar de la concentración de la oferta, no mejora el modo en que la fruta llega al mercado. Y que ello se debe a cuestiones de insuficiente normativa tanto comunitaria como canaria, así como a la falta de espíritu cooperativo. Siendo esto cierto, pues ya se vio el fracaso histórico de los grandes plataneros por dominar el comercio exterior canario, así como la fragmentación de las organizaciones de productores y sus rivalidades internas, se ha planteado que el factor determinante puede ser el paulatino control por parte de las firmas multinacionales/peninsulares, pues es en la comercialización donde se obtiene la mayor parte de la ganancia. Las organizaciones de productores son resultado de un asociacionismo forzado exigido por la OCM del plátano, pues si no se pertenece a una, no se puede cobrar la ayuda compensatoria. Pero la ayuda compensatoria favorece a los grandes cosecheros:

Hay que tener en cuenta que la ayuda directa (diferencial precios mínimos y de mercado) es una ayuda media para toda la Comunidad, de manera que al agricultor se le garantiza 60 ptas. kilo para este año. Supongamos que el año que viene el precio realmente obtenido por el platanero medio comunitario sean 40 ptas., con lo que la ayuda serían 20 ptas. Pero no todo el mundo va a obtener esas 40 ptas. Es posible que exista un buen productor, con fincas avanzadas tecnológicamente, con buenas variedades y que comercializa bien, que haya obtenido 59 ptas. kilo. Y a este productor se le dará también las mismas 20 ptas. Así clarísimamente se está premiando en el mecanismo de la OCM la Calidad del producto. (entrevista a Santiago Ubach, gerente de la cooperativa COSLO, Periódico Diario de Avisos, 30/10/93, p. 54).

Otra aportación que se ha querido dejar planteada es que no se puede entender las entidades asociativas de Canarias sin su vinculación a los agentes comerciales que intermedian la producción agropecuaria que intenta abastecer al mercado isleño. El sistema agroalimentario en Canarias deja claramente de lado a los agricultores, muchos de ellos agrupados en cooperativas, en beneficio de los agentes comerciales. Éstos (empresas importadoras, a las que se han unido las grandes cadenas de supermercados) están condicionando, cuando no subordinando, la independencia de diversas cooperativas agrarias locales, como ejemplifica el caso de la papa. Muchas cooperativas, ante la crisis de los mercados tradicionales de exportación (de tomates, papas, batatas, cebollas, etc.) están intentando diversificar sus producciones hacia el mercado regional canario, pero allí se encuentran con las mismas dificultades que la papa: la competencia de esos mismos productos importados.

El aparato del Estado con su desarrollo normativo refrenda la anterior afirmación (REF, POSEICAN y REA) pudiéndose establecer una conexión clara entre el papel preponderante de los grandes propietarios en las cooperativas, su vínculo a los agentes comerciales foráneos (peninsular-balear ligados o no a multinacionales europeas y norteamericanas) y el poder político que únicamente se ha evidenciado aquí a través de las normativas estatales (Cabildos, Comunidad Autónoma, Estado español y la Unión Europea).

Los productores directos no son nada, pero son necesarias las cooperativas puestas al servicio de las grandes empresas comercializadoras que lo son todo: de COPLACA en los setenta, a las maduradoras peninsulares en los ochenta y de ahí a la vuelta de Fyffes (multinacionales). En este artículo se ha visto

34 Por ejemplo, en referencia a la crisis de la cooperativa Unión Agrícola de Las Palmas, se leía en un artículo de opinión (Periódico La Provincia, 12/04/84, p. 13): ¿Cuáles deberían de ser los objetivos de la asamblea? Antes que nada y en cualquier caso, exigir las responsabilidades legales a que hubiere lugar, incluyendo daños y perjuicios, a los miembros de la junta rectora. Llevar el asunto a los tribunales de Justicia parece una medida de estricta higiene cooperativa. 
como los productores han sido incapaces históricamente de controlar el comercio exterior de Canarias, pues dicho control es el factor clave de una economía siempre extrovertida, volcada a la exportación de sus producciones, por lo que la evolución de su desarrollo sigue respondiendo a fuerzas externas.

\section{Agradecimientos}

Agradecemos la información suministrada por Ángela Delgado (entrevista a Ángela Delgado, Presidenta de ASAGA-Canarias y de la cooperativa LACASMI del Sur de Tenerife, 8 de julio de 2020); y Wladimiro Rodríguez (entrevista a Wladimiro Rodríguez Brito, 24 de enero 2020).

\section{Referencias}

Basanta Fernández, C. (2012). Cooperativismo agrario en la Comunidad Valenciana. Investigaciones Geográficas, 57, 101-127. https://doi.org/10.14198/INGEO2012.57.05.

Cáceres-Hernández, J. J., Martín Rodríguez, G., González Gómez, J. I. y Nuez Yánez, J. S. (2013). Exportaciones de plátano canario. ¿Son racionales las decisiones de pica? Economía Agraria y Recursos Naturales, 13(2), 77-102. https://doi.org /10.7201/earn.2013.02.04

Carnero Lorenzo, F., Barroso Ribal, C. y Nuez Yánez J. S. (2014). Análisis de la economía social en Canarias. Mercado laboral y empleo. La Laguna: Asociación Creativa-Centro de la Cultura Popular Canaria. Recuperado de https://www.researchgate.net/publication/304575979_Economia_Social_en_Canarias

Carnero Lorenzo, F. y Nuez Yánez J. S. (2002). Perspectiva histórica del cooperativismo de crédito agrícola en Canarias. CIRIEC-España Revista de Economía Pública, Social y Cooperativa, 42, 159-186.

Carnero Lorenzo, F. y Nuez Yánez, J. S. (2005). Sobre la historia económica del asociacionismo agrario en Canarias: un estado de la cuestión. XI Congreso de Historia Agraria. Aguilar de Campoo.

Carnero Lorenzo, F. y Nuez Yánez, J. S. (2015). La adaptación de las cooperativas agrarias canarias a los cambios económicos acaecidos en el último siglo. Anuario de Estudios Atlánticos, 61, 1-14.

Cooperativa Agrícola del Norte de Tenerife (1964). Bodas de oro, 1914-1964. Santa Cruz de Tenerife: Cooperativa Agrícola del Norte de Tenerife.

Delgado Aguilar, J. (1991). Apuntes para una historia del cooperativismo en Canarias. Santa Cruz de Tenerife: EFOCA.

García Rodríguez, J. L. y Pestana Pérez, G. (2010). Las Medianías. Agricultura paisaje y desarrollo rural en Canarias. La Laguna: Asociación de Geógrafos Españoles.

Garrido Herrero, S. (2003), El primer cooperativismo agrario español. CIRIEC-España Revista de Economía Pública, Social y Cooperativa, 44, 33-56.

Gil Olcina, A. (1989). El impacto del cooperativismo agrario en la organización de las áreas rurales. En V Coloquio de Geografía Agraria (pp. 543-572). Santiago de Compostela: Universidad de Santiago de Compostela.

Gómez, N. (2015). 25 años de cooperativismo agroalimentario democrático y unificado. España: Cajamar Caja Rural-Escobar Impresores.

Gómez López, J. D. (2004a). Las cooperativas agrarias de la Comunidad Valenciana frente al proceso de globalización. Cuadernos de Geografía de la Universitat de València, 75, 1-16.

Gómez López, J. D. (2004b). La reforma de la PAC y la importancia de las cooperativas agrarias en la vertebración socioeconómica y territorial del medio rural. Ería, 63, 73-90.

Hernández Hernández, J. M. (2019): Movimiento obrero y conflictividad social en el Valle de La Orotava (1918-1936). La Orotava: Ayuntamiento de La Orotava-LeCanarien Ediciones.

Jurado, E. y Cardozo, L. (2016). La cuestión espacial en la economía social y solidaria: una lectura de procesos cooperativos a partir de estudios geográficos. SaberEs, 8(1), 23-42. https://doi.org/10.35305/s. v8il.121

Luis Rodríguez. C., Luis Vega, B. y Suárez López, S. (2018). Evolución del precio del plátano. (Trabajo de Fin de Grado. Grado de Contabilidad y Finanzas). La Laguna: Facultad de Economía, Empresa y Turismo de la Universidad de La Laguna. 
Martín Martín, V. O. (1993). Un ejemplo de producción de espacio: el Canal del Sur en Tenerife. Ería, 31 , 129-138.

Martínez Rodríguez, S. (2005). El primer cooperativismo agrario español en el contexto europeo: difusión y selección de ideas. En XI Congreso de Historia Agraria. Valladolid: Universidad de Valladolid y Seminario de Historia Agraria.

Martínez Soto, Á. P. (2005). El cooperativismo alemán entre 1860-1930: sistemas y evolución. En XI Congreso de Historia Agraria. Valladolid: Universidad de Valladolid y Seminario de Historia Agraria. Recuperado de http://seha.info/pdfs/ii_asociacionismo/II-pascual2.pdf

Méndez, R. (2015). Redes de colaboración y economía alternativa para la resiliencia urbana: una agenda de investigación. Biblio 3W. Revista Bibliográfica de Geografía y Ciencias Sociales, XX(1.139). Recuperado de http://www.ub.edu/geocrit/b3w-1139.pdf

Nuez Yánez, J. S. (2005). El mercado mundial de plátanos y las empresas productoras en Canarias, 1870 2000. Santa Cruz de Tenerife: Instituto de Estudios Canarios, ASPROCAN y Caja Rural de Tenerife.

Nuez Yánez, J. S. (Dir.) (2007). Cosecheros de Tejina. Pasado y futuro de la agricultura en la comarca. 60 aniversario. Santa Cruz de Tenerife: Sociedad Cooperativa Cosecheros de Tejina.

Nuez Yánez, J. S. (2017). ¿Cuántos plataneros perciben la ayuda Posei y en qué OPP están?. Agropalca, $37,19$.

Nuez Yánez, J. S. y Carnero Lorenzo, F. (2004). Sociedad Cooperativa del Campo La Candelaria. Medio siglo. La Laguna: Sociedad Cooperativa del Campo La Candelaria.

Nuez Yánez, J. S. y Carnero Lorenzo, F. (2005a). Sobre la historia económica del asociacionismo agrario en Canarias: un estado de la cuestión. En XI Congreso de Historia Agraria (pp. 1-16). Valladolid: Universidad de Valladolid y Seminario de Historia Agraria.

Nuez Yánez, J. S. y Carnero Lorenzo, F. (2005b). El asociacionismo agrario en la Unión Europea. El caso de las Organizaciones de Productores de Plátanos de Canarias. CIRIEC-España Revista de Economía Pública, Social y Cooperativa, 51, 211-235.

Nuez Yánez, J. S., Carnero Lorenzo, F. y Barroso Ribal, C. (2005). Desarrollo rural y cooperativismo en Canarias. En Salinas Ramos, F., Erranz de la Casa, J.M. y Albarrán Fernández, C. (Coords.), Aportaciones de la economía social al desarrollo rural en Iberoamérica y España (pp. 328-369). Ávila: Universidad Católica de Ávila.

Pérez Artiles, J. (1991). El cooperativismo agrario en Canarias: un cooperativismo comercializador. La Laguna: Consejería de Agricultura y Pesca del Gobierno de Canarias.

Rebollo López, M. (2012). El tomate en Gran Canaria: cultivo, empresas, aparcería y exportación (19301970). (Singularidad en la producción y exportación del tomate canario) (Tesis doctoral). Departamento de Ciencias Históricas. Universidad de Las Palmas de Gran Canaria.

Rodríguez Brito, W. (1986). La agricultura de exportación en Canarias, 1940-1980. Santa Cruz de Tenerife: Consejería de Agricultura, Ganadería y Pesca del Gobierno de Canarias.

Román Cervantes, C. (2001). El asociacionismo agropecuario en Canarias: una perspectiva histórica. En Carnero Lorenzo, F. y Nuez Yánez, J.S. (Coords.). Empresa e Historia en Canarias (pp. 71-104). Santa Cruz de Tenerife: Fundación FYDE-CajaCanarias.

Román Cervantes, C. (2004). El cooperativismo de comercialización en Canarias (1940-2000). En XIX Jornadas de Historia Económica. Buenos Aires: Asociación Argentina de Historia Económica.

Román Cervantes, C. (2007). Asociarse y exportar: el asociacionismo agrario en Canarias, 1940-2000. Revista de Historia Canaria, 189, 133-154.

Román Cervantes, C. (2008). Las Sociedades Agrarias de Transformación en España: un análisis histórico. CIRIEC-España Revista de Economía Pública, Social y Cooperativa, 63, 65-87.

Román Cervantes, C. (2014). Las cooperativas españolas y los ciclos económicos. Un análisis comparado. CIRIEC-España, Revista de Economía Pública, Social y Cooperativa, 80, 77-109.

Román Cervantes, C. y Bruno Pérez, N. (1999). Un ejemplo de supervivencia en economía social: La cooperativa agrícola platanera "Corporación de Agricultores", La Palma (1943-1993). En Economía 
Canaria 1999. II Seminario de Economía Canaria (pp. 59-73). Las Palmas de Gran Canaria: Universidad de Las Palmas de Gran Canaria.

Segrelles Serrano, J. A. (1992). El cooperativismo ganadero español: Una actividad dinámica e insuficiente ante el Mercado Único Europeo. Ería, 29, 243-251.

Segrelles Serrano, J. A. (1994). Tendencias recientes y estrategias comerciales del cooperativismo ganadero con integración vertical en Cataluña. Agricultura y Sociedad, 72, 243-262.

Segrelles Serrano, J. A. y Maas J. H. M. (1996). Integración, cooperación y proyección exterior del sector cárnico-ganadero holandés. Revista Española de Economía Agraria, 178, 235-252.

Segrelles Serrano, J. A. (1999). Capitalismo y organización de los espacios ganaderos en España. El caso de la Cooperativa Agropecuaria de Guissona. Investigaciones Geográficas (Universidad Nacional Autónoma de México), 39, 94-108. https://doi.org/10.14350/rig.59086

Suárez Bosa, M. (1996). Los sindicatos agrícolas en Canarias en el primer tercio del siglo XX. Agricultura y Sociedad, 78, 113-138.

Suárez Bosa, M., Martínez Milán, J., Luxán Meléndez, S. y Solbes Ferri, S. (1995). Auge y crisis de los productos de exportación en el primer tercio del siglo XX en Canarias. Boletín Millares Carló-Centro Asociado UNED de Las Palmas de Gran Canaria, 14, 101-117.

Villalba Moreno, E. (1978). Estudio del cultivo del tomate en Tenerife y Gran Canaria. Santa Cruz de Tenerife: Cámara Oficial de Comercio, Industria y Navegación - Instituto Tinerfeño de Expansión Económica.

\section{Prensa periódica:}

Canarias 7. Recuperado de https://www.canarias7.es/

Diario de Avisos. Recuperado de https://diariodeavisos.elespanol.com/

Diario de Las Palmas

El Día. Recuperado de https://www.eldia.es/

El Diario. Recuperado de https://www.eldiario.es/

La Gaceta de Canarias

La Provincia/Diario de Las Palmas. Recuperado de https://www.laprovincia.es/

La Opinión de Tenerife

\section{Revistas y periódicos agrarios:}

Agropalca (Plataforma Agraria Libre de Canarias). Recuperado de http://www.palca.es/

Campo Canario. Publicación de la Asociación de Agricultores y Ganaderos de Canarias (ASAGA Canarias ASAJA). Recuperado de https://www.asaga-asaja.com/revista

Canal Agrario La Palma. Recuperado de https://canalagrariolapalma.com

Canarias Agraria y Pesquera. Recuperado de https://www.gobiernodecanarias.org/agp/sgt/servicios/ publicaciones/revista.html

Canarias Agrícola. Recuperado de https://canariasagricola.com/

Cooperativas Agroalimentarias-España. Recuperado de http://www.agro-alimentarias.coop

El Baleo. Revista bimensual de la Sociedad Cooperativa del Campo "La Candelaria".

Mundo Rural de Tenerife. Recuperado de http://www.agrocabildo.org/publicaciones.asp 